\title{
Impact of Zn Substitution on Fe(II)-induced Ferrihydrite
}

\section{Transformation Pathways}

1. Department of Earth and Planetary Sciences, Washington University in St. Louis, Saint Louis, MO 63130, USA 


\section{ABSTRACT}

Iron oxide minerals are ubiquitous in soils, sediments, and aquatic systems and influence

25 the fate and availability of trace metals. Ferrihydrite is a common iron oxide of nanoparticulate

26 size and poor crystallinity, serving as a thermodynamically unstable precursor to more crystalline

27 phases. While aging induces such phase transformations, these are accelerated by the presence of

28 dissolved Fe(II). However, the impact of trace metals on Fe(II)-catalyzed ferrihydrite phase

29 transformations at ambient temperatures and the associated effects on trace metal speciation has

30 seen limited study. In the present work, phase transformations of ferrihydrite that contains the trace

31 metal zinc in its structure were investigated during aging at ambient temperature in the presence

32 of two different $\mathrm{Fe}(\mathrm{II})$ concentrations at $\mathrm{pH}$ 7. X-ray diffraction reveals that low $\mathrm{Fe}(\mathrm{II})$

33 concentration $(0.2 \mathrm{mM})$ generates hematite plus minor lepidocrocite, whereas high $\mathrm{Fe}(\mathrm{II})$

34 concentration $(1.0 \mathrm{mM})$ promotes the production of a magnetite-lepidocrocite mixture. In both

35 cases, a substantial fraction of ferrihydrite remains after 12 days. In contrast, Zn-free ferrihydrite

36 forms primarily lepidocrocite and goethite in the presence of $0.2 \mathrm{mM} \mathrm{Fe}(\mathrm{II})$, with minor hematite

37 and a trace of ferrihydrite remaining. For $1.0 \mathrm{mM} \mathrm{Fe(II),} \mathrm{magnetite,} \mathrm{goethite,} \mathrm{and} \mathrm{lepidocrocite}$

38 form when $\mathrm{Zn}$ is absent, leaving no residual ferrihydrite. Transformations of Zn-ferrihydrite

39 produce a transient release of zinc to solution, but this is nearly quantitatively removed into the

40 mineral products after 1 hour. Extended X-ray absorption fine structure spectroscopy suggests that

41 zinc partitions into the newly formed phases, with a shift from tetrahedral to a mixture of

42 tetrahedral and octahedral coordination in the $0.2 \mathrm{mM} \mathrm{Fe}(\mathrm{II})$ system and taking on a spinel-like

43 local structure in the $1.0 \mathrm{mM}$ Fe(II) reaction products. This work indicates that substituting

44 elements in ferrihydrite may play a key role in promoting the formation of hematite in low

45 temperature systems, such as soils or sediments. In addition, the retention of zinc in the products 
46 of ferrihydrite phase transformation shows that trace metal micronutrients and contaminants may

47 not be mobilized under circumneutral conditions despite the formation of more crystalline iron

48 oxides. Furthermore, mass balance requires that the abundance and isotopic composition of iron

49 oxide-associated zinc, and possibly other trace metals, in the rock record may be retained during

50 diagenetic phase transformations of ferrihydrite if catalyzed by dissolved Fe(II).

\section{INTRODUCTION}

Ferrihydrite is a ubiquitous, naturally occurring iron oxide that is commonly found in soils

54 and aquatic environments (Combes et al., 1990; Jambor and Dutrizac, 1998; Cornell and

55 Schwertmann, 2003). It has high surface area and is nanocrystalline, producing greater reactivity

56 compared to other iron oxides (Hiemstra, 2013; Hiemstra, 2015). The fate and transport of metal

57 ions is often controlled by sorption to ferrihydrite and other iron oxide minerals (Brown and Parks,

58 2001; Scheinost et al., 2001; Manceau et al., 2007; Gustafsson et al., 2011; Eickhoff et al., 2014;

59 Tian et al., 2017). Aging of metals sorbed to ferrihydrite enhances their retention, possibly through

60 incorporation (Schultz et al., 1987; Ainsworth et al., 1994; Ford et al., 1997). In addition, metals

61 present during ferrihydrite formation may coprecipitate into the mineral structure (Martínez and

62 McBride, 1998; Ford et al., 1999; Dai et al., 2017).

63 Ferrihydrite is thermodynamically unstable with respect to other more crystalline iron

64 oxides such as lepidocrocite, goethite, and hematite (Navrotsky et al., 2008), and transforms over

65 time to these more stable phases (Schwertmann and Taylor, 1972; Cornell and Schwertmann,

66 2003). Such transformations play essential roles in determining iron oxide mineralogy in soils

67 (Kämpf and Schwertmann, 1983; Nørnberg et al., 2009; Jiang et al., 2018) as well as modern and

68 ancient sedimentary systems (Chan et al., 2007; Bekker et al., 2010). Ferrihydrite phase 
69 transformations involve competitive processes influenced by various factors, such as temperature,

70 ligand type, and pH (Fischer and Schwertmann, 1975; Schwertmann et al., 1999; Cornell and

71 Schwertmann, 2003). Hematite formation from a ferrihydrite precursor occurs rapidly at

72 temperatures of 50 to $100^{\circ} \mathrm{C}$ (Fischer and Schwertmann, 1975; Johnston and Lewis, 1983; Liu et

73 al., 2005; Das et al., 2011; Soltis et al., 2016; Jiang et al., 2018) but at 4 to $30^{\circ} \mathrm{C}$ requires years of

74 aging (Schwertmann and Murad, 1983; Schwertmann et al., 1999; Schwertmann et al., 2000b;

75 Schwertmann et al., 2000a; Schwertmann et al., 2004; Das et al., 2011). Goethite is promoted over

76 hematite at cooler temperature, higher humidity, and at either acidic or alkaline $\mathrm{pH}$ (Torrent et al.,

77 1982; Schwertmann and Murad, 1983; Nagano et al., 1994; Das et al., 2011; Zhang et al., 2018).

Ferrihydrite transformation to more crystalline phases can be rapidly induced by dissolved

$79 \mathrm{Fe}(\mathrm{II})$. At ambient temperatures, this process yields lepidocrocite, goethite, and, at elevated Fe(II)

80 concentrations, magnetite (Tronc et al., 1992; Hansel et al., 2003; Hansel et al., 2005; Pedersen et

81 al., 2005; Yee et al., 2006; Liu et al., 2007; Yang et al., 2010; Hansel et al., 2011; Boland et al.,

82 2013; Boland et al., 2014; Liu et al., 2016; Tomaszewski et al., 2016; Jones et al., 2017). Hematite

83 also occurs when ferrihydrite reacts with dissolved Fe(II) at elevated temperature, typically $60{ }^{\circ} \mathrm{C}$

84 or greater (Hansel et al., 2005; Liu et al., 2005; Pedersen et al., 2005; Liu et al., 2008; Wang et al.,

85 2015). Fe(II) catalyzed transformations to goethite and lepidocrocite involve adsorption and

86 electron transfer at the mineral surface, producing a reactive Fe(III) species that facilitates mass

87 transfer, growth, and formation of new phases (Boland et al., 2014; Sheng et al., 2020b). Ligand

88 type impacts ferrihydrite transformation pathways: chloride favors the transformation of

89 ferrihydrite to lepidocrocite, while sulfate supports the conversion to both goethite and

90 lepidocrocite (Hansel et al., 2005; Liu et al., 2008). pH variations affect the formation of magnetite,

91 the relative amounts of goethite and lepidocrocite produced, and the rate of ferrihydrite 
92 transformation (Hansel et al., 2005; Boland et al., 2014). Surface adsorbates, including silicate and

93 organic matter, both slow ferrihydrite transformation and alter the final minerals that form (Jones

94 et al., 2009; Wang et al., 2015; Thomasarrigo et al., 2018; Xiao et al., 2018; Zhou et al., 2018;

95 Thomasarrigo et al., 2019; Sheng et al., 2020a). Aluminum substitution diminishes secondary

96 mineralization and enhances preservation of ferrihydrite, requiring greater Fe(II) concentrations to

97 induce transformation compared to Al-free ferrihydrite (Masue-Slowey et al., 2011; Hansel et al., 98 2011).

Trace metals also impact ferrihydrite transformations. At $70^{\circ} \mathrm{C}$, coprecipitated divalent 100 metal cations may either promote or inhibit ferrihydrite transformation in Fe(II)-free systems 101 (Cornell, 1988; Martínez and McBride, 1998). Dissolved Zn alters thermal transformation 102 products of ferrihydrite at $70^{\circ} \mathrm{C}$, increasing hematite content at the expense of goethite through a 103 Zn-maghemite precursor while also forming franklinite because of the high Zn concentrations used 104 (Sakakibara et al., 2019). At ambient temperature, adsorbed divalent cations (Liu et al., 2016) or 105 rare earth elements (Fei et al., 2018) inhibit Fe(II)-catalyzed ferrihydrite transformations and alter 106 the amounts of goethite, lepidocrocite, and magnetite that formed. No prior studies have reported 107 that metals promote hematite formation near $25^{\circ} \mathrm{C}$ or cooler.

108 Despite the extensive study of ferrihydrite conversion to other minerals, the role of 109 incorporated trace metals in affecting $\mathrm{Fe}(\mathrm{II})$-catalyzed ferrihydrite transformations and the 110 resulting fate of such metals is poorly understood at ambient temperatures. This study thus 111 investigates the behavior of $\mathrm{Zn}$ during $\mathrm{Fe}(\mathrm{II})$-induced ferrihydrite transformations at $22^{\circ} \mathrm{C}$. Batch 112 aging experiments were carried out in which Zn-substituted ferrihydrite was exposed to $0.2 \mathrm{mM}$ 113 or $1.0 \mathrm{mM}$ dissolved $\mathrm{Fe}(\mathrm{II})$ at $\mathrm{pH} 7$ for 12 days. X-ray diffraction (XRD) patterns collected over 114 the course of the experiment tracked the mineralogical evolution, with mineral abundances 
115 quantified via Rietveld refinement. Concentrations of dissolved $\mathrm{Zn}$ and Fe were measured over

116 time to study the release and uptake of $\mathrm{Zn}$ as well as the consumption and adsorption of $\mathrm{Fe}(\mathrm{II})$. X-

117 ray absorption fine structure (XAFS) spectra were obtained to evaluate the coordination state of

118 Zn associated with iron oxide minerals at different aging times.

120 2. MATERIALS AND METHODS

121 2.1. Mineral Synthesis

122 Zn-substituted ferrihydrite was synthesized using a modification of previously described

123 methods for the 2-line form of this mineral (Schwertmann and Cornell, 2000). $73.5 \mathrm{~mL}$ of $5 \mathrm{M}$

124 sodium hydroxide was added dropwise over 20 minutes into a $125 \mathrm{~mL}$ solution containing $0.98 \mathrm{M}$

125 ferric nitrate and $0.02 \mathrm{M}$ zinc chloride that was continuously stirred. Solution $\mathrm{pH}$ was continuously

126 measured and maintained below $\mathrm{pH}$ 11, as high $\mathrm{pH}$ favors the formation of goethite. The resulting

127 suspension was then centrifuged at $15000 \mathrm{rpm}$ for 20 minutes. After centrifugation, the majority

128 of the supernatant was decanted off, and the precipitate was resuspended in ultrapure water $(>18.2$

$129 \mathrm{M} \Omega \mathrm{cm}$ ) and then centrifuged again. This process was repeated 6 times until the particles would

130 no longer settle during centrifugation, indicating a substantial decrease in ionic strength. After the

131 final centrifugation, ferrihydrite was resuspended in ultrapure water; the $\mathrm{pH}$ of this suspension was

132 6.9. The suspension was then freeze dried and stored in polypropylene bottles wrapped in

133 aluminum foil at room temperature. The drying step was done to inhibit changes in ferrihydrite

134 properties associated with aging as a suspension (Hiemstra et al., 2019) and to maintain a single

135 batch of Zn-substituted ferrihydrite for use in multiple experiments. Zn-free ferrihydrite was

136 prepared using the same procedure but with the initial $125 \mathrm{~mL}$ solution containing $1.0 \mathrm{M}$ ferric

137 nitrate and no added zinc chloride. 


\subsection{Mineral Transformation Experiments}

All solutions were prepared in an anaerobic chamber (Coy Laboratory Products) in a 3\% $\mathrm{H}_{2}$ and $\sim 97 \% \mathrm{~N}_{2}$ atmosphere that was circulated over a $\mathrm{Pd}$ catalyst to eliminate residual $\mathrm{O}_{2}$.

141 Ultrapure water was deoxygenated by bubbling for at least 5 hours with ultrahigh purity $\mathrm{N}_{2}(<1$ 142 ppmv $\mathrm{O}_{2}$ ) before being transferred into the glove box. The oxygen level in the deoxygenated 143 ultrapure water was further lowered by sparging with anaerobic chamber atmosphere that was first 144 bubbled through a 10\% pyrogallol/40\% potassium hydroxide solution, which serves as a secondary 145 oxygen trap that also scavenges $\mathrm{CO}_{2}$. Dissolved oxygen was measured colorimetrically using 146 CHEMets test kit K-7540 to confirm a concentration below the $\sim 1 \mu \mathrm{g} / \mathrm{L}$ detection limit.

147 Synthesized ferrihydrite with and without structural Zn was brought into the glove box at least 48 148 hours prior to use. All salts used were ACS reagent grade or better and were prepared in the 149 anaerobic chamber as stock solutions.

150 Experiments were conducted in solutions containing final concentrations of $10^{-2} \mathrm{M}$ sodium 151 chloride, $10^{-3}$ M 3-(N-Morpholino) propanesulfonic acid (MOPS, a pH buffer with a pKa value of 152 7.20), and either $1.0 \mathrm{mM}$ or $0.2 \mathrm{mM}$ dissolved Fe(II), prepared from iron(II) chloride tetrahydrate. 153 The initial pH was adjusted to 7.0 using $0.1 \mathrm{~N} \mathrm{NaOH}$ and $0.1 \mathrm{~N} \mathrm{HCl}$. A Zn-substituted ferrihydrite 154 suspension was prepared at an initial concentration of $4 \mathrm{~g} / \mathrm{L}$ of ground, freeze-dried ferrihydrite in 155 deoxygenated deionized water. A desired volume of the suspension was injected into to the sample 156 solution to reach a final concentration of $1 \mathrm{~g} / \mathrm{L}$. Addition of Zn-ferrihydrite marked the start of the 157 reaction. Each experiment was conducted in a $500 \mathrm{~mL}$ polypropylene bottle with the fluid 158 continuously stirred using a magnetic stirrer with a PTFE-coated magnet. The bottle was wrapped 159 in aluminum foil to inhibit photoreduction and the cap was sealed using vinyl tape to decrease the 160 possibility of residual oxygen in the anaerobic chamber from inadvertently oxidizing the solution. 
161 The $\mathrm{pH}$ of the solution was checked, recorded, and adjusted back to $7.00 \pm 0.05$ daily during the

162 reaction. $20 \mathrm{~mL}$ subsamples of the well-mixed suspension were removed after 2 minutes, 5 minutes,

16315 minutes, 1 hour, 2 hours, 4 hours, 7 hours, 1 day, 3 days, 5 days, 7 days, and 12 days. Each was

164 immediately filtered using a $0.22 \mu \mathrm{m}$ mixed cellulose ester (MCE) membrane in a polypropylene

165 syringe filter enclosure. Ferrihydrite aggregation was adequate to allow separation of particles

166 from the fluid via filtration as confirmed by the lack of dissolved Fe measured in Fe(II)-free control

167 samples. Duplicates were collected on days 7 and 12 to assess the reproducibility of the

168 measurements. The filtered fluids were then removed from the anaerobic chamber and acidified

169 with 2\% trace meal grade nitric acid before dissolved Fe and Zn concentrations were measure by

170 inductively-coupled plasma mass spectrometry (ICP-MS) using a Thermo iCAP Q instrument.

171 Minerals collected on the filter membranes were dried in a vacuum desiccator inside the anaerobic

172 chamber for further characterization.

173 A set of control experiments were carried out in separate tubes to evaluate possible sources

174 of experimental error and to assess the impact of dissolved Fe(II) and substituting $\mathrm{Zn}$ on the

175 reactions. Two control experiments were prepared with the same fluid composition as described 176 above (one for each Fe(II) concentration) but no minerals were added in order to evaluate possible 177 sample contamination with Zn, as has been noted in prior work (Kay, 2004; Bryan et al., 2015;

178 Garçon et al., 2017). Two additional control experiments (again, one for each Fe(II) concentration)

179 replicated the studies described above by added Zn-free ferrihydrite instead of Zn-substituted 180 ferrihydrite. Mineral and filtered fluid samples were collected after 12 days of reaction for these 181 control experiments. 


\subsection{Mineral characterization}

Mineral solids were analyzed by powder X-ray diffraction (XRD) using a Bruker d8 Advance diffractometer equipped with a Cu X-ray tube operating at $40 \mathrm{kV}$ and $40 \mathrm{~mA}$. The initial synthetic ferrihydrite samples and the solids collected after select reaction times were studied. Minerals were ground using an agate mortar and pestle and mounted on a zero-background silicon sample holder. XRD scans were performed from $15^{\circ}$ to $85^{\circ}$ with a $0.02^{\circ}$ step-size, 0.5 s count time per step at a rotation rate of 15 rotations per minute. A LynxEye XE energy-dispersive siliconstrip detector was used for data collection in a continuous scan mode, with each of the 192 detector strips measuring the same angular position for the specified counting time. This yielded a total integration time of 96 s per $2 \theta$ value. The Diffrac.Eva application was used for initial phase identification. Rietveld refinement of the XRD patterns determined the quantitative abundances of crystalline phases and the semi-quantitative abundance of ferrihydrite using a partially empirical approach (see Electronic Annex). Fitting was conducted in the Profex (Doebelin and Kleeberg, 2015) interface to BGMN (Bergmann et al., 1998). Brunauer-Emmett-Teller (BET) specific surface area of each synthesized mineral was determined by collecting $\mathrm{N}_{2}$ gas adsorption isotherms using a Quantachrome Autosorb-1 Instrument. The Zn concentration in Zn-substituted ferrihydrite was determined by acid digestion. $5 \mathrm{mg}$ of ferrihydrite was dissolved in $10 \mathrm{~mL}$ of $4 \mathrm{M}$ hydrochloric acid at $70^{\circ} \mathrm{C}$. The solution was then diluted $1: 100$ using $2 \%$ trace metal grade nitric acid and measured by ICP-MS.

\subsection{X-ray absorption fine structure spectroscopy}

Zn K-edge XAFS spectra, including the X-ray absorption near-edge structures (XANES) and extended X-ray absorption fine-structure (EXAFS) regions, were measured on the initial Zn- 
207 ferrihydrite, a Zn-hematite standard, and the solid-phase products formed from reaction of Zn208 ferrihydrite with $0.2 \mathrm{mM} \mathrm{Fe}(\mathrm{II})$ for $2 \mathrm{~h}$ and $12 \mathrm{~d}$ with $1.0 \mathrm{mM} \mathrm{Fe}(\mathrm{II})$ after 12 days. Preparation of 209 the Zn-hematite standard was described in a prior study (Frierdich et al., 2012). Data collection 210 was performed on beamline 12-BM-B at the Advanced Photon Source (APS) at Argonne National 211 Laboratory. The beamline employed a Si (111) fixed offset monochromator which was detuned $21230 \%$ to reduce the harmonic content of the beam. Toroidal focusing and flat mirrors were used to 213 increase usable X-ray flux and further reduce harmonics, with focusing effects resulting in a beam 214 of $\sim 700 \mu \mathrm{m}$ diameter. Zn K-edge data were collected in fluorescence yield with a 13-element 215 energy-dispersive Ge detector. Aluminum foil was used to selectively reduce the Fe fluorescence 216 intensity in order to prevent detector saturation. An additional standard of $\mathrm{Zn}$ adsorbed to hematite 217 was prepared by reacting $0.2 \mathrm{mM}$ zinc chloride with $4 \mathrm{~g} \mathrm{~L}^{-1}$ synthetic hematite in a $0.01 \mathrm{M}$ sodium 218 chloride solution for 5 days at $\mathrm{pH}$ 7.5. Details of the hematite synthesis and sample preparation 219 follow procedures described previously (Frierdich et al., 2011). The Zn K-edge XAFS spectrum 220 of this additional sample was measured at APS beamline 20-BM-B using similar optics and 221 detector details as those described above.

222 The X-ray energy for all measurements was calibrated by setting the maximum in the first 223 derivative of the X-ray absorption near-edge structure spectrum of a Zn metal foil to $9659 \mathrm{eV}$ for 224 the Zn K-edge. XAFS spectral scans were averaged using the Athena (Ravel and Newville, 2005) 225 interface to IFEFFIT (Newville, 2001). The normalized and background subtracted $\mathrm{k}^{3}$-weighted 226 EXAFS spectra of Zn were fitted to structural models in SixPACK (Webb, 2005) using phase and 227 amplitude functions generated from the structure of franklinite (Verwey and Heilmann, 1947) 228 using FEFF 7.02 (Ankudinov and Ravel, 1998). Spectra were fit in $k$-space over a range of 3.0 to $22911.3 \AA$ and in R-space from 1.0 to $4.0 \AA$ for all samples and standards. The coordination number 
$230(\mathrm{~N})$, interatomic distances $(\mathrm{R}), \sigma^{2}$ (a Debye-Waller-type factor based on a Guassian distribution 231 of interatomic distances), and $\Delta \mathrm{E}_{0}$ were refined using nonlinear least-squares fitting. The

232 amplitude reduction factor $\left(\mathrm{S}_{0}{ }^{2}\right)$ was fixed at 0.9 for spectral fitting. Linear combination fitting in 233 select cases was conducted in Athena.

\section{3. RESULTS}

236

237

238

239

240

241

242

243

244

245

246

247

248

249

250

251

252

\subsection{Characterization of Zn-ferrihydrite and Zn-free Ferrihydrite}

XRD reveals that Zn-ferrihydrite contained no detectable crystalline impurities, yielding a pattern consistent with that of 2-line ferrihydrite (Fig. 1a). Zn-free ferrihydrite generated an XRD pattern indistinguishable from the Zn-substituted phase. The Zn content of the substituted ferrihydrite determined by acid digestion was $2.2 \mathrm{~mol} \%$, close to the target substitution level of 2.0 mol.\%. The BET specific surface areas for Zn-free ferrihydrite and Zn-ferrihydrite are 297 $\mathrm{m}^{2} / \mathrm{g}$ and $233 \mathrm{~m}^{2} / \mathrm{g}$, respectively. Structural analysis of the Zn K-edge EXAFS spectrum (Fig. 1b) of Zn-ferrihydrite shows that Zn substitutes in tetrahedral configuration, as indicated by the Zn-O interatomic distance and coordination number (Table 1). The Zn-Fe distance of 3.45 $\AA$ (Table 1) indicates corner-sharing between a zinc tetrahedron and an iron octahedron, a geometry also consistent with zinc substituting into the proposed tetrahedral iron site in ferrihydrite (Michel et al., 2007; Michel et al., 2010; Maillot et al., 2011).

\subsection{Phase Transformations of Zn-ferrihydrite}

\subsubsection{Transformations in $0.2 \mathrm{mM} \mathrm{Fe}(\mathrm{II})$}

Upon contact with $0.2 \mathrm{mM}$ dissolved Fe(II), Zn-ferrihydrite showed no evidence of converting to more crystalline phases over the first few hours of reaction (Fig. 2). By $1 \mathrm{~d}$ of reaction, 
253 initial hematite peaks appeared in the XRD pattern, with both hematite and lepidocrocite clearly

254 present after $3 \mathrm{~d}$ of reaction. These continued to grow in through the $12 \mathrm{~d}$ duration of the

255 experiment (Fig. 2). The broad ferrihydrite peaks persisted throughout much of the reaction, with

256 weak background features present at $\sim 35^{\circ}$ and $\sim 63^{\circ} 2 \theta$. Rietveld refinement of the XRD data (Fig.

257 S2) quantified the crystalline phases formed and provided a semi-quantitative estimate of

258 ferrihydrite abundance (Fig. 3) using an empirical approach described in the Electronic Annex.

259 This analysis shows that hematite was the dominant crystalline product formed from Zn-

260 ferrihydrite over the course of reaction, with lepidocrocite present as 10-20 wt.\% of the crystalline

261 phases. Ferrihydrite transformed slowly and only partially converted to crystalline phases after 12

$262 \mathrm{~d}$ of reaction, with more than $50 \mathrm{wt} . \%$ of the initial ferrihydrite remaining (Fig. 3).

263

264 3.2.2 Transformations in 1.0 mM Fe(II)

265 In a $1.0 \mathrm{mM}$ Fe(II) solution, Zn-ferrihydrite transforms more rapidly (Fig. 2). After $2 \mathrm{~h}$ of 266 reaction, the first time point sampled, substantial lepidocrocite peaks are present. Magnetite peaks

267 appear in the XRD pattern after $1 \mathrm{~d}$ and become substantial components after $3 \mathrm{~d}$ of reaction. The 268 relative peak intensities of lepidocrocite and magnetite are stable between 5 and $12 \mathrm{~d}$ of reaction.

269 Similar to the $0.2 \mathrm{mM} \mathrm{Fe}(\mathrm{II})$ experiment, the data continued to have a background feature near $270 \sim 35^{\circ} 2 \theta$, suggesting that some ferrihydrite remained unreacted. Rietveld refinement of the XRD

271 data (Fig. S3) confirms that lepidocrocite dominated the crystalline products over the first day of

272 reaction but this evolved to a subequal mixture with magnetite that appeared to stabilize in relative

273 proportions by $5 \mathrm{~d}$ of reaction (Fig. 4). While Zn-ferrihydrite transformation was more rapid

274 compared to the $0.2 \mathrm{mM} \mathrm{Fe}(\mathrm{II})$ experiment, a substantial residual component ( $35 \mathrm{wt} . \%$ ) remained 275 after 12 d (Fig. 4). 


\subsubsection{Control Experiments}

Control experiments were conducted to evaluate the role of $\mathrm{Zn}$ and $\mathrm{Fe}(\mathrm{II})$ in generating the

278 observed mineral products (Fig. 5). Aging Zn-ferrihydrite for $12 \mathrm{~d}$ in the absence of dissolved

$279 \mathrm{Fe}(\mathrm{II})$ yielded no detectable phase transformation, with the XRD pattern preserving the features of

280 2-line ferrihydrite (Fig. 5). Zn-free ferrihydrite reacted with $0.2 \mathrm{mM}$ dissolved Fe(II) for $12 \mathrm{~d}$

281 produced substantial lepidocrocite and goethite peaks and minor hematite peaks in the XRD

282 pattern (Fig. 5). Notably, goethite was absent in the Zn-ferrihydrite experiment under the same

283 conditions and aging time (Fig. 2). Full-pattern fitting via Rietveld refinement (Fig. S4) required

284 a mixture of lepidocrocite, goethite, and hematite to reproduce the data. This showed that the

285 crystalline products contained $~ 35$ wt.\% goethite, which did not form when the starting solid was

286 Zn-ferrihydrite. The lepidocrocite content of the crystalline phases was also substantially increased

287 for Zn-free ferrihydrite. In addition, hematite was only 25 wt.\% of the crystalline fraction of the

288 solids compared to $>80 \mathrm{wt}$ \% of the crystalline phases in the Zn-ferrihydrite experiment. Only 10

289 wt.\% ferrihydrite remained after reaction, compared to $>50 \mathrm{wt} . \%$ for Zn-ferrihydrite.

290 Reaction of Zn-free ferrihydrite with $1.0 \mathrm{mM}$ dissolved Fe(II) for $12 \mathrm{~d}$ also produced

291 distinct mineralogy compared to Zn-ferrihydrite. While a mixture of magnetite and lepidocrocite

292 still formed, goethite was also present, similar to the $0.2 \mathrm{mM} \mathrm{Fe}(\mathrm{II})$ control experiment. Magnetite

293 abundance was $\sim 50 \mathrm{wt} . \%$ of the crystalline products, approximately the same percentage as in the

294 Zn-ferrihydrite experiment, but less lepidocrocite formed at the expense of goethite (Fig. 3).

295 Ferrihydrite was below detection limit, producing greater conversion of $\mathrm{Zn}$-free ferrihydrite 296 compared to Zn-ferrihydrite. 


\subsection{Zn Release and Uptake during Phase Transformations}

300

301

302

303

304

305

306

307

308

309

310

311 312 solid phase.

313

\section{4}

315

316

317

318

319

320

\subsubsection{Transformations in $0.2 \mathrm{mM} \mathrm{Fe}(\mathrm{II})$}

Zinc release and uptake and the removal of dissolved iron were monitored during the transformation of $\mathrm{Zn}$-ferrihydrite in the presence of $0.2 \mathrm{mM} \mathrm{Fe}(\mathrm{II})$. At the beginning of the reaction, $\mathrm{Zn}$ is rapidly released to solution, with a dissolved concentration of $\sim 20 \mu \mathrm{M} \mathrm{Zn}$ at the first time point (Fig. 6A). Zn was then progressively taken up into the solid phase, with near-complete removal of Zn initially released to the fluid. On the third day, Zn concentration reaches the lowest value of $0.7 \mu \mathrm{M}$ and then gradually increased to $2 \mu \mathrm{M}$ by the end of the $12 \mathrm{~d}$ experiment. The residual dissolved $\mathrm{Zn}$ consists of only $1 \%$ of the total $\mathrm{Zn}$ in the system, indicating that $99 \%$ is retained in the solid phase during phase transformation after the brief transient release during the first few minutes of reaction. The dissolved Fe concentration (Fig. 6B) similarly decreases rapidly at the beginning of the reaction and then gradually increased from day 3 to 12 . The final dissolved Fe concentration was $27 \mu \mathrm{M}$, indicating that $>86 \%$ of the initial dissolved Fe(II) was bound to the

\subsubsection{Transformations in 1.0 mM Fe(II)}

The concentrations of dissolved $\mathrm{Zn}$ and Fe for $\mathrm{Zn}$-ferrihydrite in contact with an initial 1.0 mM Fe(II) solution (Fig. 6C,D) follow patterns similar to the experiment with lower Fe(II) concentration (Fig. 6A,B). At the beginning of the reaction, $\sim 22 \mu \mathrm{M}$ Zn was rapidly released from Zn-ferrihydrite. Within one day, the dissolved Zn concentration displayed a drastic drop. After the third day of reaction, Zn concentration in the solution was $\sim 7 \mu \mathrm{M}$, which is $3 \%$ of the initial $\mathrm{Zn}$ concentration. More than $97 \%$ of $\mathrm{Zn}$ was retained in the solid phase. 
The dissolved Fe concentration experienced a sharp drop during the first hour of reaction

322 followed by a slower decline to less than $10 \mu \mathrm{M}$ by day 5 , with $>99 \%$ of the initial dissolved Fe(II)

323 partitioning into the solid phase. During the period of large declines in dissolved Fe(II)

324 concentration, the $\mathrm{pH}$ drifted down from $\mathrm{pH} 7.0$ to as low as 6.6, despite the presence of a buffer

325 in the experiment. At each sampling point the $\mathrm{pH}$ was thus manually adjusted to back to 7.0 \pm 0.1

326 by dropwise addition of $0.1 \mathrm{M} \mathrm{NaOH}$ (Fig. S5). This adjustment was performed after removal of

327 an aliquot of the suspension for fluid and solid-phase analyses.

328

\subsubsection{Control Experiments}

Control experiments were carried out in parallel to both $0.2 \mathrm{mM}$ and $1.0 \mathrm{mM}$ Fe(II) experiments to further ensure the accuracy of the studies involving dissolved Fe(II) and to help

332 interpret the results. In control sample with $10^{-2} \mathrm{M} \mathrm{NaCl}, 10^{-3} \mathrm{M} \mathrm{MOPS}, 0.2 \mathrm{mM}$ Fe(II) and no 333 mineral addition, the Zn concentration measured after $12 \mathrm{~d}$ of aging was $0.03 \mu \mathrm{M}$, indicating that

334 Zn contamination was not a substantial contributor to the observed results. The total dissolved Fe 335 concentration was $144 \mu \mathrm{M}$ after $12 \mathrm{~d}$, suggesting that either a portion of the Fe(II) adsorbed to the 336 reactor walls or was oxidized, although this concentration was substantially greater than the final 337 concentration in the corresponding experiment with Zn-ferrihydrite. In a control sample with $10^{-2}$ $338 \mathrm{M} \mathrm{NaCl}, 10^{-3} \mathrm{M}$ MOPS, $1.0 \mathrm{mM}$ Fe(II) and no mineral addition, the dissolved Zn concentration 339 was $0.31 \mu \mathrm{M}$ after $12 \mathrm{~d}$. While lower in concentration that the final $\mathrm{Zn}$ concentration in the 340 experiment with Zn-ferrihydrite, it does suggest a minor source of contamination, possibly from

341 trace amounts of $\mathrm{Zn}$ in the salts used. The dissolved Fe concentration after $12 \mathrm{~d}$ was $984 \mu \mathrm{M}$, 342 suggesting negligible adsorption or oxidation occurred. 


\subsection{Spectroscopic Characterization of Zn}

The interaction of Zn with ferrihydrite during phase transformation can be inferred from

the structural information provided by EXAFS spectroscopy. Zn has various coordination states, with tetrahedral and octahedral Zn most common (Waychunas et al., 2002). Previous studies have reported that $\mathrm{Zn}$ (II) adsorbs on ferrihydrite as a tetrahedral complex, maintaining this geometry but with a greater number of Fe neighbors when coprecipitated (Waychunas et al., 2002; Juillot et al., 2008). In contrast, dissolved Zn(II) is octahedrally coordinated and surface complexes on hematite and goethite occur as both tetrahedral and octahedral species (Juillot et al., 2008; Ha et al., 2009). Zn substitutes into hematite and goethite as octahedral species, although these may be substantially distorted (Frierdich and Catalano, 2012; Bylaska et al., 2019). These observations are noted as they guide the structural model fitting approach used in this study.

The EXAFS spectra show that Zn coordination changes substantially during Fe(II)catalyzed phase transformations of ferrihydrite (Fig. 7). During transformations induced by 0.2 $\mathrm{mM}$ Fe(II), the EXAFS spectrum of a sample collected after $2 \mathrm{~h}$ show little variation from the initial unreacted Zn-ferrihydrite (Fig. 7). Structural analysis confirms that Zn coordination does not detectably change over this time period (Table 1). In contrast, after $12 \mathrm{~d}$ of reaction with 0.2

361 (Table 1) show that a mixture of octahedral and tetrahedral $\mathrm{Zn}$ is present and a second $\mathrm{Zn}-\mathrm{Fe}$ 362 distance occurs at $2.97 \AA$. In addition, the longer Zn-Fe distance shortens slightly to $3.40 \AA$. These 363 distances are similar to those observed for Zn substituting into hematite (Table 1), the dominant 364 ferrihydrite transformation product in the sample. Visually, the EXAFS spectrum of the $12 \mathrm{~d}$ 365 sample displays some muted features potentially similar to $\mathrm{Zn}$ in hematite, including a shift to 366 lower $k$ of the maxima near $4 \AA^{-1}$ and two apparent oscillations between 7 and $9 \AA^{-1}$. 
However, Zn incorporation into hematite alone does not fully explain its speciation in the

$36812 \mathrm{~d}$ sample. Linear-combination fitting well reproduces the spectrum of Zn-ferrihydrite reacted

369 with $0.2 \mathrm{mM} \mathrm{Fe(II)} \mathrm{for} 12 \mathrm{~d}$ using the spectra of Zn-ferrihydrite, Zn-hematite, and Zn adsorbed to

370 hematite (see the Electronic Annex for structural analysis of the hematite standards). This analysis

371 indicates that a large fraction of the $\mathrm{Zn}(\sim 75 \%)$ is either incorporated into hematite or occurs in an

372 adsorbed form, with 25\% retained in ferrihydrite. However, the resulting low component sum

373 (0.94) suggests that the spectral standards are not fully adequate. We attribute this to possible

374 mixtures of tetrahedral and octahedral surface complexes (Ha et al., 2009) not well represented by

375 the Zn adsorption to hematite standard. In addition, this analysis does not account for the minor

376 lepidocrocite component present in the mineral assemblage. Despite these minor discrepancies,

377 the structural analysis and linear combination fitting both indicate that a substantial fraction of $\mathrm{Zn}$

378 has redistributed from ferrihydrite to hematite and likely occurs in both incorporated and adsorbed

379 forms.

380 Reaction of Zn-ferrihydrite with $1.0 \mathrm{mM}$ Fe(II) for $12 \mathrm{~d}$ produces more substantial changes

381 in the EXAFS spectrum of Zn (Fig. 8). Notably, the spectrum has similar fine-structure as the 382 spectrum of franklinite, but with weaker oscillations. Structural model fitting (Table 1) is 383 consistent with Zn occupying a tetrahedral site in a ferrite spinel structure. For example, Zn in 384 franklinite has 4 oxygen neighbors at $1.98 \AA$ and 12 iron neighbors at $3.50 \AA$ (Pavese et al., 2000) 385 and the tetrahedral site in magnetite has 12 iron neighbors at $3.48 \AA$ (Fleet, 1981). Zn likely occurs 386 as a substituting element in the abundant magnetite produced in this reaction because franklinite 387 was not detected via XRD (Fig. 2). Linear-combination fitting reproduces the data well with a 388 mixture of franklinite and Zn-ferrihydrite (Fig. 8). However, some features are offset in $k$, 389 consistent with the effects on EXAFS spectra of slight differences in interatomic distances between 
390 franklinite and magnetite. This analysis does not account for an $\mathrm{Zn}$ adsorbed to magnetite or 391 associated with lepidocrocite. However, the EXAFS data clearly indicate that $\mathrm{Zn}$ partitions into 392 ferrihydrite transformation products at the higher Fe(II) concentration present in this experiment.

\section{4. DISCUSSION}

\subsection{Impact of Fe(II) Concentration on Ferrihydrite Transformation Pathways}

Multiple prior studies demonstrate that $\mathrm{Fe}(\mathrm{II})$ concentration determines whether $\mathrm{Fe}(\mathrm{II})$ acts as a catalyst or reactant during ferrihydrite phase transformations (Tronc et al., 1992; Hansel et al., 2003; Hansel et al., 2005; Pedersen et al., 2005; Yang et al., 2010; Boland et al., 2014). In general, Fe(II) concentrations below approximately $0.4 \mathrm{mM}$ favor the catalysis of ferrihydrite conversion to more crystalline Fe(III) (oxyhyd)roxides, including goethite and lepidocrocite (Yee et al., 2006;

401 Liu et al., 2007), while at higher concentrations Fe(II) is consumed to also generate magnetite 402 (Hansel et al., 2003; Hansel et al., 2005; Pedersen et al., 2005; Yang et al., 2010). The Fe(II) 403 concentration needed to generate magnetite varies among different studies and is likely impacted 404 by $\mathrm{pH}$, ferrihydrite concentration, the anions present, and other factors. Our studies are consistent 405 with past experiments, finding that $0.2 \mathrm{mM}$ dissolved Fe(II) initiates only catalytic transformations, 406 with all products consisting of ferric iron minerals. The higher concentration explored, $1.0 \mathrm{mM}$, 407 generated substantial magnetite via reaction between Fe(II) and ferrihydrite. Note that while the 408 fractional abundance of crystalline products of $\mathrm{Zn}$-ferrihydrite transformation was dominated by 409 lepidocrocite at early times, the absolute abundance (Table S1) increases to $37 \pm 3 \mathrm{wt} . \%$ after $1 \mathrm{~d}$ 410 before stabilizing at $32 \pm 3 \mathrm{wt} . \%$ by $12 \mathrm{~d}$. There thus appear to be little to no lepidocrocite 411 conversion to magnetite; lepidocrocite simply forms first with ample Zn-ferrihydrite remaining.

412 The absolute abundance of lepidocrocite at $1 \mathrm{~d}$ is affected by the amount of ferrihydrite identified 
413 using our semi-quantitative method via Rietveld refinement, and the potential small decline in

414 absolute lepidocrocite abundance over time may reflect systematic errors in the analysis rather

415 than real changes in mineralogy.

416

$417 \quad 4.2$ Impact of Zinc on Ferrihydrite Transformation Pathways

418 4.1 Promotion of Low-Temperature Hematite Formation

419 While hematite is the most thermodynamically stable phase among the common iron

420 oxides in aqueous environments, its formation from ferrihydrite at ambient temperatures is slow

421 (Cornell and Schwertmann, 2003) and the addition of Fe(II) under such conditions is not reported

422 to produce this phase on timescales up to 9 days. Ferrihydrite stored in water over a large range of

$423 \mathrm{pH}$ values (2 to 12 ) at temperatures of 4 to $30{ }^{\circ} \mathrm{C}$ converted to hematite after 9.3 to 12.6 years

424 (Schwertmann et al., 1999), with hematite first apparent at $25^{\circ} \mathrm{C}$ after 100 s of days at pH 7 (Das

425 et al., 2011). Hematite can also be produced at short timescales by heating ferrihydrite in water at

426 elevated temperatures (Johnston and Lewis, 1983; Das et al., 2011). In addition, hematite was

427 generated after heating ferrihydrite for 180 days at $45^{\circ} \mathrm{C}$ and $55^{\circ} \mathrm{C}$ at a relative humidity of nearly

428 100\% (Torrent et al., 1982). This demonstrates that ferrihydrite to hematite conversion is

429 kinetically slow without a catalyst present or thermal input. While catalytic ferrihydrite

430 transformations induced by $\mathrm{Fe}(\mathrm{II})$ have not been reported to produce hematite at ambient

431 temperatures (Hansel et al., 2003; Hansel et al., 2005; Pedersen et al., 2005; Lee et al., 2006;

432 Boland et al., 2014), this product is observed for Fe(II)-ferrihydrite systems when heated at $60^{\circ} \mathrm{C}$

433 to $100^{\circ} \mathrm{C}$ (Liu et al., 2005; Liu et al., 2007; Liu et al., 2008).

434 In contrast to prior work, the present study observed rapid hematite formation from Zn-

435 substituted 2-line ferrihydrite at room temperature $\left(22^{\circ} \mathrm{C}\right)$ at $\mathrm{pH} 7$. Hematite clearly nucleated 
436 within three days of reaction, with the first signs of hematite in XRD patterns possibly present

437 after one day. In addition, hematite was the dominant (>80\%) crystalline product throughout the

438 reaction. The rapid and pervasive formation of hematite is clearly related to the presence of

439 substituting $\mathrm{Zn}$ as only minor hematite formed in the Zn-free control study. The promotion of

440 hematite by Zn has been previously demonstrated in a recent thermal transformation study

441 conducted at $70^{\circ} \mathrm{C}$ (Sakakibara et al., 2019). However, the present study is the first to document

442 that Zn promotes rapid hematite formation from ferrihydrite at ambient temperatures.

\section{$444 \quad$ 4.2.2. Inhibition of Goethite Formation}

Zinc also appears to inhibit goethite formation during Fe(II)-promoted ferrihydrite

446 transformation. This phase was absent in studies of Zn-ferrihydrite but was a substantial crystalline

447 product in the Zn-free control experiments. The formation of substantial goethite from Zn-free

448 ferrihydrite in $0.2 \mathrm{mM} \mathrm{Fe}(\mathrm{II})$ was accompanied by greater lepidocrocite formation than in the Zn-

449 ferrihydrite studies. In contrast, more goethite forms from Zn-free ferrihydrite at the apparent 450 expense of lepidocrocite in $1.0 \mathrm{mM}$ Fe(II). Zinc does not clearly affect the formation of magnetite, 451 with similar amounts forming from Zn-ferrihydrite and Zn-free ferrihydrite. This demonstrates 452 that Zn affects crystallization pathways beyond promoting hematite formation.

454 4.2.3. Inhibition of Ferrihydrite Transformation

455 Zinc also slows ferrihydrite transformation, leaving a substantial residual ferrihydrite pool 456 after $12 \mathrm{~d}$. Prior work suggests that a surface competition mechanism may play a role in inhibiting 457 transformation. Adsorption of metals of higher binding affinities than Fe(II), such as $\mathrm{Zn}(\mathrm{II})$, slow 458 the transformation rate of ferrihydrite by obstructing the Fe(II) binding to the surface (Liu et al., 
2016). The release of metals from the goethite and hematite structures is also affected by the

460 relative adsorption affinity of $\mathrm{Fe}(\mathrm{II})$ and the metal ion, which was attributed to reduced rates of

461 recrystallization when metals are present (Frierdich and Catalano, 2012). The transient release of

462 Zn in our study and its re-adsorption on mineral surfaces may thus hinder further transformation

463 of ferrihydrite.

\subsection{Processes Controlling Dissolved Zn and Fe Concentrations}

At the beginning of the low Fe(II) $(0.2 \mathrm{mM})$ transformation experiment, $\mathrm{Zn}$ is transiently

467 released into the solution. This may have been caused by rapid displacement of near-surface $\mathrm{Zn}$

468 by the adsorption of Fe(II), which also showed a rapid initial decline. Fe(II) uptake continued

469 during the initial stages of the reaction through the third day, when hematite first showed

470 substantial nucleation. We hypothesize that during these initial days the Fe(II) uptake rate was

471 controlled by diffusion into ferrihydrite aggregates. Zn concentrations also decreased during this

472 time. While this would appear contradictory with the concept of its rapid release driven be

473 competitive effects, it is possible that as Fe(II) continued to react it underwent electron transfer,

474 with electrons migrating into the bulk mineral structure (Williams and Scherer, 2004; Handler et

475 al., 2009; Boland et al., 2013). This may have reverted the surface of ferrihydrite particles to being

476 dominated by Fe(III), making re-adsorption of Zn more favorable. The slight rebound in dissolved

$477 \mathrm{Zn}$ and $\mathrm{Fe}(\mathrm{II})$ concentrations after the third day may then relate to the increasing presence of

478 coarser, crystalline iron oxides, which provide less specific surface area and thus a lower capacity

479 to adsorb these species. EXAFS spectroscopy showed that a substantial portion of the Zn initially

480 in ferrihydrite partitions into new mineral phases. This incorporation may thus mute the impact of

481 grain size coarsening on Zn adsorption. A portion of the increase in Zn concentration may also be 
482

483

484

485

486

487

488

489

490

491

492

493

494

495

496

497

498

499

500

501

502

503

504

attributable to Fe(II)-promoted recrystallization of hematite and lepidocrocite (Frierdich et al., 2011; Frierdich and Catalano, 2012; Latta et al., 2012). This has been demonstrated to release structural Zn to solution for hematite (Frierdich and Catalano, 2012). While it has not been clearly demonstrated yet for lepidocrocite, it has been shown for goethite and may be a general phenomenon for crystalline iron oxides (Frierdich and Catalano, 2012; Frierdich et al., 2012).

In the high $\mathrm{Fe}(\mathrm{II})(1.0 \mathrm{mM})$ ferrihydrite transformation experiment, dissolved $\mathrm{Zn}$ and $\mathrm{Fe}$ concentrations behave similarly to what is observed in low Fe(II) experiment. The rapid initial release of Zn plus the rapid decline of both concentrations can again be attributed for the adsorption-desorption processes discussed above. Notably, Zn and Fe concentrations do not rebound at the later stages of reaction, unlike the experiment at lower Fe(II) concentration. A substantial decline in dissolved Fe concentration between day 1 and 3 corresponds to a large increase in magnetite content. Adsorption may thus have been responsible for the initial decline in dissolved Fe concentration to $\sim 0.6 \mathrm{mM}$, with the larger drop to $\sim 10 \mu \mathrm{M}$ caused by net Fe(II) consumption during magnetite formation. The near-complete sequestration of $\mathrm{Zn}$ in the solidphase is also likely associated with Zn uptake into the magnetite structure, as indicated by EXAFS spectroscopy. For both systems studied, Zn fate is controlled by both adsorption and incorporation into the secondary iron oxide products.

\subsection{Geological and Environmental Implications}

\subsubsection{Promotion of Low-Temperature Hematite Formation}

This study reports rapid formation of hematite from ferrihydrite at $22^{\circ} \mathrm{C}$. The presence of Zn clearly accelerates hematite formation, a product not previously observed during Fe(II)catalyzed ferrihydrite transformation at ambient temperatures (Hansel et al., 2003; Hansel et al., 
2005; Pedersen et al., 2005; Yee et al., 2006). The role of Zn itself in forming hematite in natural

506 systems may be limited because it is unlikely that ferrihydrite in the environment will contain $\mathrm{Zn}$

507 at the level ( 2 mol.\%) explored in the present study, except perhaps near weathering zinc sulfide

508 ore deposits. However, a wide array of substituting elements are commonly associated with iron

509 oxides in nature (Schwertmann and Cornell, 2000; Cornell and Schwertmann, 2003). The present

510 results suggest a general mechanism where substituting elements in ferrihydrite enhance the

511 conversion to hematite, helping to nucleate this phase at temperatures lower than is typically

512 observed in laboratory studies. While further study is warranted, impurities may play key roles in

513 promoting low-temperature hematite formation in the environment.

515 4.4.2. Potential Impact on Metal Stable Isotope Records

516 The near-quantitative retention of Zn during Fe(II)-promoted phase transformations, both

517 to ferric oxyhydroxides and to magnetite, suggests that such transformations do not perturb solid-

518 phase trace metal stable isotope compositions. Solid-aqueous fractionation factors between $\mathrm{Zn}$

519 adsorbed to iron oxide minerals and dissolved $\mathrm{Zn}$ are generally $<0.5 \%$ in magnitude (Pokrovsky

520 et al., 2005; Balistrieri et al., 2008; Juillot et al., 2008). We are unaware of studies of isotopic

521 fractionation involving $\mathrm{Zn}$ incorporated into iron oxides, but adsorption-desorption would be a

522 critical intermediate step that may dictate fractionation. With $>97 \%$ retention in the solid phase,

523 such partitioning could alter the Zn stable isotope composition of the solid phases by $<0.015 \%$,

524 much less than the typical analytical precision Zn stable isotope measurements (0.04 to $0.1 \%$ )

525 (Balistrieri et al., 2008; Chen et al., 2009; Moynier et al., 2017). This demonstrates that the

526 transformation processes observed in the present study will not measurably alter solid-phase $\mathrm{Zn}$

527 stable isotope compositions from that of primary ferrihydrite precipitates, such as during 
528 diagenesis. Conditions that lead to lower $\mathrm{Zn}$ retention, such as transformations under more acidic

$529 \mathrm{pH}$, may potentially perturb such values.

\section{4.4.3. Implications for Bioessential Trace Metal Availability}

532 Elements such as cobalt, nickel, copper, and zinc serve as key reaction centers in

533 metalloenzymes (Gärtner et al., 1993; Ermler et al., 1997; Thauer, 1998; Brown et al., 2000; Parks

534 et al., 2013; Zheng et al., 2016) and low availability of these metals may inhibit microbial processes

535 in environment (Schönheit et al., 1979; Granger and Ward, 2003; Ekstrom and Morel, 2008; Glass

536 and Orphan, 2012; Lu et al., 2018). Previous study has suggested that metal solubility can be

537 reduced through coprecipitation with or removal by iron oxides formed during ferrihydrite

538 transformation (Martínez and McBride, 1998). In the current work, the retention of a high portion

539 of Zn in phase transformation products suggests that trace metal micronutrients are not mobilized

540 by formation of more crystalline iron oxides. The observed Zn retention indicates that the

541 availability of this metal is not enhanced during Fe(II)-promoted ferrihydrite transformations

542 except during the first hour of reaction. However, subsequent Zn release during Fe(II)-promoted

543 recrystallization of the more crystalline transformation products (Frierdich et al., 2011; Frierdich

544 and Catalano, 2012) may later enhance metal availability. It is unclear whether similar behavior

545 will be displayed by other bioessential metals, such as $\mathrm{Co}$ and $\mathrm{Ni}$, as their solid-water partitioning 546 may be distinct from $\mathrm{Zn}$ because of differences in ionic radii and chemical properties.

548 5. CONCLUSION

549 The trace metal Zn alters the Fe(II)-induced transformation pathways of ferrihydrite and 550 partially incorporates into the resulting crystalline iron oxides. This study is the first to report that 
551 Zn promotes the formation of hematite at $22^{\circ} \mathrm{C}$, which occurs as the dominant reaction product for

552 systems containing $0.2 \mathrm{mM}$ dissolved Fe(II). This suggests that impurity ions may be critical to

553 the formation of hematite in low-temperature environments. In addition, $\mathrm{Zn}$ inhibits both goethite

554 formation and the overall transformation of ferrihydrite to more crystalline phases. A small

555 fraction of the ferrihydrite-bound $\mathrm{Zn}$ is released to solution during reaction but is rapidly taken

556 back up into the solid phase, partially incorporating into hematite and magnetite. Near-quantitative

557 retention of $\mathrm{Zn}$ demonstrates that ferrihydrite phase transformations at $\mathrm{pH} 7$ from interactions with

558 dissolved $\mathrm{Fe}(\mathrm{II})$ will preserve the $\mathrm{Zn}$ isotopic composition. The $\mathrm{Zn}$ to Fe ratio will also be

559 unperturbed except when magnetite or other mixed-valent phases form through net Fe(II) uptake;

560 the additional Fe would dilute the Zn content. Such transformations may thus preserve chemical

561 or isotopic signatures associated with $\mathrm{Zn}$ in modern soils or aquatic systems as well as in the

562 sedimentary record. Finally, ferrihydrite phase transformations will not substantially limit trace

563 metal contaminant sequestration or micronutrient availability despite the formation of more

564 crystalline mineral products if fluid conditions favor solid-phase retention.

\section{ACKNOWLEDGEMENT}

567 The project was supported by the International Center for Energy, Environment and 568 Sustainability at Washington University in Saint Louis. Addition support for J.G.C. and J.Y. was 569 provided by the U.S. National Science Foundation (NSF), Environmental Chemical Sciences 570 program through award no. CHE-1709484 and the U.S. Department of Energy (DOE), Office of 571 Science, Office of Biological and Environmental Research, Subsurface Biogeochemical Research 572 program through award no. DE-SC0019422. Preparation of the standards for zinc associated with 573 hematite was supported by the U.S. NSF Faculty Early Career Development Program through 
574 award no. EAR-1056480. ICP-MS analyses were performed in the Isotope Cosmochemistry

575 laboratory at the Department of Earth and Planetary Sciences at Washington University. We thank

576 Prof. Kun Wang and Dr. Heng Chen for their help with ICP-MS measurements. BET

577 measurements were conducted at the Nano Research and Environmental Laboratory at Washington

578 University. XAFS data were collected at beamline 12-BM-B at the Advanced Photon Source, a

579 U.S. DOE Office of Science User Facility operated for the DOE Office of Science by Argonne

580 National Laboratory under Contract No. DE-AC02-06CH11357. We thank Dr. Benjamin Reinhart

581 for assistance with XAFS data collection.

582

\section{APPENDIX A. SUPPLEMENTARY MATERIAL}

584 A supplementary material document associated with this manuscript contains a description of the semi-quantitative determination of ferrihydrite abundance via Rietveld refinement, a description of the EXAFS fitting results for Zn incorporated in and adsorbed on hematite, figures of the Rietveld refinement fitting results, plots of the $\mathrm{pH}$ drift over time during the aging experiments, Zn K-edge XANES spectra of Zn-ferrihydrite, its reaction products, and associated standards, and 589 a table of the Rietveld refinement results.

\section{REFERENCES}

592

593

594
Ainsworth C. C., Gassman P. L., Pilon J. L. and Van Der Sluys W. G. (1994) Cobalt, cadmium, and lead sorption to hydrous iron oxide: Residence time effect. Soil Sci. Soc. Am. J. 58, $1615-1623$.

Ankudinov A. and Ravel B. (1998) Real-space multiple-scattering calculation and interpretation of x-ray-absorption near-edge structure. Phys. Rev. B - Condens. Matter Mater. Phys. 58, 7565-7576.

Balistrieri L. S., Borrok D. M., Wanty R. B. and Ridley W. I. (2008) Fractionation of Cu and Zn isotopes during adsorption onto amorphous Fe(III) oxyhydroxide: Experimental mixing of acid rock drainage and ambient river water. Geochim. Cosmochim. Acta 72, 311-328.

Bekker A., Slack J. F., Planavsky N., Krapež B., Hofmann A., Konhauser K. O. and Rouxel O. J. 
602

603

604

605

606

607

608

609

610

611

612

613

614

615

616

617

618

619

620

621

622

623

624

625

626

627

628

629

630

631

632

633

634

635

636

637

638

639

640

641

642

643

644

645

646

647

(2010) Iron formation: The sedimentary product of a complex interplay among mantle, tectonic, oceanic, and biospheric processes. Econ. Geol. 105, 467-508.

Bergmann J., Friedel P. and Kleeberg R. (1998) BGMN—a new fundamental parameters based Rietveld program for laboratory $\mathrm{X}$-ray sources, its use in quantitative analysis and structure investigations. CPD Newsl. 20, 5-8.

Boland D. D., Collins R. N., Glover C. J. and David Waite T. (2013) An in situ quick-EXAFS and redox potential study of the Fe(II)-catalysed transformation of ferrihydrite. Colloids Surfaces A Physicochem. Eng. Asp. 435, 2-8.

Boland D. D., Collins R. N., Miller C. J., Glover C. J. and Waite T. D. (2014) Effect of solution and solid-phase conditions on the $\mathrm{Fe}(\mathrm{II})$-accelerated transformation of ferrihydrite to lepidocrocite and goethite. Environ. Sci. Technol. 48, 5477-5485.

Brown G. E. and Parks G. A. (2001) Sorption of trace elements on mineral surfaces: Modern perspectives from spectroscopic studies, and comments on sorption in the marine environment. Int. Geol. Rev. 43, 963-1073.

Brown K., Tegoni M., Prudêncio M., Pereira A. S., Besson S., Moura J. J., Moura I. and Cambillau C. (2000) A novel type of catalytic copper cluster in nitrous oxide reductase. Nat. Struct. Biol. 7, 191-195.

Bryan A. L., Dong S., Wilkes E. B. and Wasylenki L. E. (2015) Zinc isotope fractionation during adsorption onto Mn oxyhydroxide at low and high ionic strength. Geochim. Cosmochim. Acta 157, 182-197.

Bylaska E. J., Catalano J. G., Mergelsberg S. T., Saslow S. A., Qafoku O., Prange M. P. and Ilton E. S. (2019) Association of defects and zinc in hematite. Environ. Sci. Technol. 53, 13687-13694.

Chan M. A., Ormö J., Park A. J., Stich M., Souza-Egipsy V. and Komatsu G. (2007) Models of iron oxide concretion formation: Field, numerical, and laboratory comparisons. Geofluids 7, 356-368.

Chen J.-B., Louvat P., Gaillardet J. and Birck J.-L. (2009) Direct separation of Zn from dilute aqueous solutions for isotope composition determination using multi-collector ICP-MS. Chem. Geol. 259, 120-130.

Combes J. M., Manceau A. and Calas G. (1990) Formation of ferric oxides from aqueous solutions: A polyhedral approach by X-ray Absorption Spectroscopy: II. Hematite formation from ferric gels. Geochim. Cosmochim. Acta 54, 1083-1091.

Cornell R. M. (1988) The influence of some divalent cations on the transformation of ferrihydrite to more crystalline products. Clay Miner. 23, 329-332.

Cornell R. M. and Schwertmann U. (2003) The Iron Oxides., VCH Publishers, New York.

Dai C., Lin M. and Hu Y. (2017) Heterogeneous Ni- and Cd-bearing ferrihydrite precipitation and recrystallization on quartz under acidic pH condition. ACS Earth Sp. Chem. 1, 621-628.

Das S., Hendry M. J. and Essilfie-Dughan J. (2011) Transformation of two-line ferrihydrite to goethite and hematite as a function of $\mathrm{pH}$ and temperature. Environ. Sci. Technol. 45, 268275.

Doebelin N. and Kleeberg R. (2015) Profex: a graphical user interface for the Rietveld refinement program BGMN. J. Appl. Crystallogr. 48, 1573-1580.

Eickhoff M., Obst M., Schröder C., Hitchcock A. P., Tyliszczak T., Martinez R. E., Robbins L. J., Konhauser K. O. and Kappler A. (2014) Nickel partitioning in biogenic and abiogenic ferrihydrite: The influence of silica and implications for ancient environments. Geochim. Cosmochim. Acta 140, 65-79. 
Ekstrom E. B. and Morel F. M. M. (2008) Cobalt limitation of growth and mercury methylation in sulfate-reducing bacteria. Environ. Sci. Technol. 42, 93-99.

Ermler U., Grabarse W., Shima S., Goubeaud M. and Thauer R. K. (1997) Crystal structure of methyl-coenzyme M reductase: The key enzyme of biological methane formation. Science 278, 1457-1462.

Fei Y., Hua J., Liu C., Li F., Zhu Z., Xiao T., Chen M., Gao T., Wei Z. and Hao L. (2018) Aqueous $\mathrm{Fe}(\mathrm{II})$-induced phase transformation of ferrihydrite coupled adsorption/immobilization of rare earth elements. Minerals 8, 357.

Fischer W. R. and Schwertmann U. (1975) The formation of hematite from amorphous iron(III)hydroxide. Clays Clay Miner. 23, 33-37.

Fleet M. E. (1981) The structure of magnetite. Acta Crystallogr. Sect. B Struct. Crystallogr. Cryst. Chem. 37, 917-920.

Ford R. G., Bertsch P. M. and Farley K. J. (1997) Changes in transition and heavy metal partitioning during hydrous iron oxide aging. Environ. Sci. Technol. 31, 2028-2033.

Ford R. G., Kemner K. M. and Bertsch P. M. (1999) Influence of sorbate-sorbent interactions on the crystallization kinetics of nickel- and lead-ferrihydrite coprecipitates. Geochim. Cosmochim. Acta 63, 39-48.

Frierdich A. J. and Catalano J. G. (2012) Controls on Fe(II)-activated trace element release from goethite and hematite. Environ. Sci. Technol. 46, 1519-1526.

Frierdich A. J., Luo Y. and Catalano J. G. (2011) Trace element cycling through iron oxide minerals during redox-driven dynamic recrystallization. Geology 39, 1083-1086.

Frierdich A. J., Scherer M. M., Bachman J. E., Engelhard M. H., Rapponotti B. W. and Catalano J. G. (2012) Inhibition of trace element release during Fe(II)-activated recrystallization of Al-, Cr-, and Sn-substituted goethite and hematite. Environ. Sci. Technol. 46, 10031-10039.

Garçon M., Sauzéat L., Carlson R. W., Shirey S. B., Simon M., Balter V. and Boyet M. (2017) Nitrile, latex, neoprene and vinyl gloves: A primary source of contamination for trace element and $\mathrm{Zn}$ isotopic analyses in geological and biological samples. Geostand. Geoanalytical Res. 41, 367-380.

Gärtner P., Ecker A., Fischer R., Linder D., Fuchs G. and Thauer R. K. (1993) Purification and properties of N5-methyltetrahydromethanopterin: coenzyme M methyltransferase from Methanobacterium thermoautotrophicum. Eur. J. Biochem. 213, 537-545.

Glass J. B. and Orphan V. J. (2012) Trace metal requirements for microbial enzymes involved in the production and consumption of methane and nitrous oxide. Front. Microbiol. 3, 1-20.

Granger J. and Ward B. B. (2003) Accumulation of nitrogen oxides in copper-limited cultures of denitrifying bacteria. Limnol. Oceanogr. 48, 313-318.

Gustafsson J. P., Tiberg C., Edkymish A. and Kleja D. B. (2011) Modelling lead(II) sorption to ferrihydrite and soil organic matter. Environ. Chem. 8, 485-492.

Ha J., Trainor T. P., Farges F. and Brown G. E. (2009) Interaction of aqueous Zn(II) with hematite nanoparticles and microparticles. Part 1. EXAFS study of Zn(II) adsorption and precipitation. Langmuir 25, 5574-5585.

Handler R. M., Beard B. L., Johnson C. M. and Scherer M. M. (2009) Atom exchange between aqueous Fe ( II ) and goethite: An Fe isotope tracer study. 43, 1102-1107.

Hansel C. M., Benner S. G. and Fendorf S. (2005) Competing Fe(II)-induced mineralization pathways of ferrihydrite. Environ. Sci. Technol. 39, 7147-7153.

Hansel C. M., Benner S. G., Neiss J., Dohnalkova A., Kukkadapu R. K. and Fendorf S. (2003) Secondary mineralization pathways induced by dissimilatory iron reduction of ferrihydrite 
694

under advective flow. Geochim. Cosmochim. Acta 67, 2977-2992.

Hansel C. M., Learman D. R., Lentini C. J. and Ekstrom E. B. (2011) Effect of adsorbed and substituted $\mathrm{Al}$ on $\mathrm{Fe}(\mathrm{II})$-induced mineralization pathways of ferrihydrite. Geochim. Cosmochim. Acta 75, 4653-4666.

Hiemstra T. (2015) Formation, stability, and solubility of metal oxide nanoparticles: Surface entropy, enthalpy, and free energy of ferrihydrite. Geochim. Cosmochim. Acta 158, 179198.

Hiemstra T. (2013) Surface and mineral structure of ferrihydrite. Geochim. Cosmochim. Acta 105, 316-325.

Hiemstra T., Mendez J. C. and Li J. (2019) Evolution of the reactive surface area of ferrihydrite: Time, $\mathrm{pH}$, and temperature dependency of growth by Ostwald ripening. Environ. Sci. Nano 6, 820-833.

Jambor J. L. and Dutrizac J. E. (1998) Occurrence and constitution of natural and synthetic ferrihydrite, a widespread iron oxyhydroxide. Chem. Rev. 98, 2549-2585.

Jiang Z., Liu Q., Roberts A. P., Barrón V., Torrent J. and Zhang Q. (2018) A new model for transformation of ferrihydrite to hematite in soils and sediments. Geology 46, 987-990.

Johnston J. H. and Lewis D. G. (1983) A detailed study of the transformation of ferrihydrite to hematite in an aqueous medium at $92^{\circ} \mathrm{C}$. Geochim. Cosmochim. Acta 47, 1823-1831.

Jones A. M., Collins R. N., Rose J. and Waite T. D. (2009) The effect of silica and natural organic matter on the $\mathrm{Fe}(\mathrm{II})$-catalysed transformation and reactivity of $\mathrm{Fe}(\mathrm{III})$ minerals. Geochim. Cosmochim. Acta 73, 4409-4422.

Jones A. M., Collins R. N. and Waite T. D. (2017) Redox characterization of the Fe(II)-catalyzed transformation of ferrihydrite to goethite. Geochim. Cosmochim. Acta 218, 257-272.

Juillot F., Maréchal C., Ponthieu M., Cacaly S., Morin G., Benedetti M., Hazemann J. L., Proux O. and Guyot F. (2008) Zn isotopic fractionation caused by sorption on goethite and 2-Lines ferrihydrite. Geochim. Cosmochim. Acta 72, 4886-4900.

Kämpf N. and Schwertmann U. (1983) Goethite and hematite in a climosequence in southern Brazil and their application in classification of kaolinitic soils. Geoderma 29, 27-39.

Kay A. R. (2004) Detecting and minimizing zinc contamination in physiological solutions. BMC Physiol. 4, 1-9.

Kelly S. D., Hesterberg D. and Ravel B. (2008) Analysis of soils and minerals Using X-ray absorption spectroscopy. In Methods of Soil Analysis Soil Science Society of America, Madison. pp. 387-463.

Latta D. E., Gorski C. A. and Scherer M. M. (2012) Influence of Fe 2+ -catalysed iron oxide recrystallization on metal cycling. Biochem. Soc. Trans. 40, 1191-1197.

Lee K., Kostka J. E. and Stucki J. W. (2006) Comparisons of structural Fe reduction in smectites by bacteria and dithionite: An infrared spectroscopic study. Clays Clay Miner. 54, 195-208.

Liu C., Zhu Z., Li F., Liu T., Liao C., Lee J. J., Shih K., Tao L. and Wu Y. (2016) Fe(II)-induced phase transformation of ferrihydrite: The inhibition effects and stabilization of divalent metal cations. Chem. Geol. 444, 110-119.

Liu H., Guo H., Li P. and Wei Y. (2008) The transformation of ferrihydrite in the presence of trace Fe(II): The effect of the anionic media. J. Solid State Chem. 181, 2666-2671.

Liu H., Li P., Zhu M., Wei Y. and Sun Y. (2007) Fe(II)-induced transformation from ferrihydrite to lepidocrocite and goethite. J. Solid State Chem. 180, 2121-2128.

Liu H., Wei Y. and Sun Y. (2005) The Formation of hematite from ferrihydrite using Fe(II) as a catalyst. J. Mol. Catal. A Chem. 226, 135-140. 
Lu X., Johs A., Zhao L., Wang L., Pierce E. M. and Gu B. (2018) Nanomolar copper enhances mercury methylation by desulfovibrio desulfuricans ND132. Environ. Sci. Technol. Lett. 5, 372-376.

Maillot F., Morin G., Wang Y., Bonnin D., Ildefonse P., Chaneac C. and Calas G. (2011) New insight into the structure of nanocrystalline ferrihydrite: EXAFS evidence for tetrahedrally coordinated iron(III). Geochim. Cosmochim. Acta 75, 2708-2720.

Manceau A., Lanson M. and Geoffroy N. (2007) Natural speciation of Ni, Zn, Ba, and As in ferromanganese coatings on quartz using X-ray fluorescence, absorption, and diffraction. Geochim. Cosmochim. Acta 71, 95-128.

Martínez C. E. and McBride M. B. (1998) Coprecipitates of Cd, $\mathrm{Cu}, \mathrm{Pb}$ and $\mathrm{Zn}$ in iron oxides: Solid phase transformation and metal solubility after aging and thermal treatment. Clays Clay Miner. 46, 537-545.

Masue-Slowey Y., Loeppert R. H. and Fendorf S. (2011) Alteration of ferrihydrite reductive dissolution and transformation by adsorbed As and structural Al: Implications for As retention. Geochim. Cosmochim. Acta 75, 870-886.

Michel F. M., Barrón V., Torrent J., Morales M. P., Serna C. J., Boily J. F., Liu Q., Ambrosini A., Cismasu A. C. and Brown G. E. (2010) Ordered ferrimagnetic form of ferrihydrite reveals links among structure, composition, and magnetism. Proc. Natl. Acad. Sci. U. S. A. 107, 2787-2792.

Michel F. M., Ehm L., Antao S. M., Lee P. L., Chupas P. J., Liu G., Strongin D. R., Schoonen M. A. A., Phillips B. L. and Parise J. B. (2007) The structure of ferrihydrite, a nanocrystalline material. Science 316, 1726-1729.

Moynier F., Vance D., Fujii T. and Savage P. (2017) The isotope geochemistry of zinc and copper. Rev. Mineral. Geochemistry 82, 543-600.

Nagano T., Nakashima S., Nakayama S. and Senoo M. (1994) The use of color to quantify the effects of $\mathrm{pH}$ and temperature on the crystallization kinetics of goethite under highly alkaline conditions. Clays Clay Miner. 42, 226-234.

Navrotsky A., Mazeina L. and Majzlan J. (2008) Size-driven structural and thermodynamic complexity in iron oxides. Science 319, 1635-1638.

Newville M. (2001) IFEFFIT: Interactive XAFS analysis and FEFF fitting. J. Synchrotron Radiat. 8, 322-324.

Nørnberg P., Vendelboe A. L., Gunnlaugsson H. P., Merrison J. P., Finster K. and Jensen S. K. (2009) Comparison of the mineralogical effects of an experimental forest fire on a goethite/ferrihydrite soil with a topsoil that contains hematite, maghemite and goethite. Clay Miner. 44, 239-247.

Parks J. M., Johs A., Podar M., Bridou R., Hurt R. A., Smith S. D., Tomanicek S. J., Qian Y., Brown S. D., Brandt C. C., Palumbo A. V., Smith J. C., Wall J. D., Elias D. A. and Liang L. (2013) The genetic basis for bacterial mercury methylation. Science 339, 1332-1335.

Pavese A., Levy D. and Hoser A. (2000) Cation distribution in synthetic zinc ferrite (Zn0.97Fe2.02O4) from in situ high-temperature neutron powder diffraction. Am. Mineral. 85, 1497-1502.

Pedersen H. D., Postma D., Jakobsen R. and Larsen O. (2005) Fast transformation of iron oxyhydroxides by the catalytic action of aqueous Fe(II). Geochim. Cosmochim. Acta 69, 3967-3977.

Pokrovsky O. S., Viers J. and Freydier R. (2005) Zinc stable isotope fractionation during its adsorption on oxides and hydroxides. J. Colloid Interface Sci. 291, 192-200. 
Ravel B. and Newville M. (2005) ATHENA, ARTEMIS, HEPHAESTUS: Data analysis for Xray absorption spectroscopy using IFEFFIT. J. Synchrotron Radiat. 12, 537-541.

Sakakibara M., Tanaka M., Takahashi Y. and Murakami T. (2019) Redistribution of Zn during transformation of ferrihydrite: Effects of initial Zn concentration. Chem. Geol. 522, 121134.

Scheinost A. C., Abend S., Pandya K. I. and Sparks D. L. (2001) Kinetic controls on Cu and Pb sorption by ferrihydrite. Environ. Sci. Technol. 35, 1090-1096.

Schönheit P., Moll J. and Thauer R. K. (1979) Nickel, cobalt, and molybdenum requirement for growth of Methanobacterium thermoautotrophicum. Arch. Microbiol. 123, 105-107.

Schultz M. F., Benjamin M. M. and Ferguson J. F. (1987) Adsorption and desorption of metals on ferrihydrite: Reversibility of the reaction and sorption properties of the regenerated solid. Environ. Sci. Technol. 21, 863-869.

Schwertmann U. and Cornell R. M. (2000) Iron Oxides in the Laboratory: Preparation and Synthesis., VCH Publishers, New York.

Schwertmann U., Friedl J. and Stanjek H. (1999) From Fe(III) ions to ferrihydrite and then to hematite. J. Colloid Interface Sci. 223, 215-223.

Schwertmann U., Friedl J., Stanjek H. and Schulze D. G. (2000a) The effect of Al on Fe oxides. XIX. Formation of Al-substituted hematite from ferrihydrite at $25^{\circ} \mathrm{C}$ and $\mathrm{pH} 4$ to 7 . Clays Clay Miner. 48, 159-172.

Schwertmann U., Friedl J., Stanjek H. and Schulze D. G. (2000b) The effect of clay minerals on the formation of goethite and hematite from ferrihydrite after 16 years' ageing at $25^{\circ} \mathrm{C}$ and pH 4-7. Clay Miner. 35, 613-623.

Schwertmann U. and Murad E. (1983) Effect of pH on the formation of goethite and hematite from ferrihydrite. Clays Clay Miner. 31, 277-284.

Schwertmann U., Stanjek H. and Becher H.-H. (2004) Long-term in vitro transformation of 2line ferrihydrite to goethite/hematite at 4, 10, 15 and $25^{\circ} \mathrm{C}$. Clay Miner. 39, 433-438.

Schwertmann U. and Taylor R. M. (1972) The transformation of lepidocrocite to goethite. Clays Clay Miner. 20, 151-158.

Sheng A., Li X., Arai Y., Ding Y., Rosso K. M. and Liu J. (2020a) Citrate controls Fe(II)catalyzed transformation of ferrihydrite by complexation of the labile Fe(III) intermediate. Environ. Sci. Technol. 54, 7309-7319.

Sheng A., Liu J., Li X., Qafoku O., Collins R. N., Jones A. M., Pearce C. I., Wang C., Ni J., Lu A. and Rosso K. M. (2020b) Labile Fe(III) from sorbed Fe(II) oxidation is the key intermediate in Fe(II)-catalyzed ferrihydrite transformation. Geochim. Cosmochim. Acta 272, 105-120.

Soltis J. A., Feinberg J. M., Gilbert B. and Penn R. L. (2016) Phase transformation and particlemediated growth in the formation of hematite from 2-Line ferrihydrite. Cryst. Growth Des. 16, 922-932.

Thauer R. K. (1998) Biochemistry of methanogenesis: a tribute to Marjory Stephenson:1998 Marjory Stephenson Prize Lecture. Microbiology 144, 2377-2406.

Thomasarrigo L. K., Byrne J. M., Kappler A. and Kretzschmar R. (2018) Impact of organic matter on iron(II)-catalyzed mineral transformations in ferrihydrite-organic matter coprecipitates. Environ. Sci. Technol. 52, 12316-12326.

Thomasarrigo L. K., Kaegi R. and Kretzschmar R. (2019) Ferrihydrite growth and transformation in the presence of ferrous iron and model organic ligands. Environ. Sci. Technol. 53, 13636-13647. 
Tian L., Shi Z., Lu Y., Dohnalkova A. C., Lin Z. and Dang Z. (2017) Kinetics of cation and oxyanion adsorption and desorption on ferrihydrite: Roles of ferrihydrite binding sites and a unified model. Environ. Sci. Technol. 51, 10605-10614.

Tomaszewski E. J., Cronk S. S., Gorski C. A. and Ginder-Vogel M. (2016) The role of dissolved $\mathrm{Fe}(\mathrm{II})$ concentration in the mineralogical evolution of $\mathrm{Fe}$ (hydr)oxides during redox cycling. Chem. Geol. 438, 163-170.

Torrent J., Guzman R. and Parra M. A. (1982) Influence of relative humidity on the crystallization of Fe(III) oxides from ferrihydrite. Clays Clay Miner. 30, 337-340.

Tronc E., Belleville P., Jolivet J. P. and Livage J. (1992) Transformation of ferric hydroxide into spinel by Fe(II) adsorption. Langmuir 8, 313-319.

Verwey E. J. W. and Heilmann E. L. (1947) Physical properties and cation arrangement of oxides with spinel structures I. Cation arrangement in spinels. J. Chem. Phys. 15, 174-180.

Wang X., Zhu M., Lan S., Ginder-Vogel M., Liu F. and Feng X. (2015) Formation and secondary mineralization of ferrihydrite in the presence of silicate and Mn(II). Chem. Geol. 415, 37-46.

Waychunas G. A., Fuller C. C. and Davis J. A. (2002) Surface complexation and precipitate geometery for aqueous $\mathrm{Zn}(\mathrm{II})$ sorption on ferrihydrite I: X-ray absorption extended fine structure spectroscopy analysis. Geochim. Cosmochim. Acta 66, 1119-1137.

Webb S. M. (2005) SIXpack: A graphical user interface for XAS analysis using IFEFFIT. Phys. Scr. T T115, 1011-1014.

Williams A. G. B. and Scherer M. M. (2004) Spectroscopic evidence for Fe(II)-Fe(III) electron transfer at the iron oxide-water interface. Environ. Sci. Technol. 38, 4782-4790.

Xiao W., Jones A. M., Collins R. N. and Waite T. D. (2018) Investigating the effect of ascorbate on the $\mathrm{Fe}(\mathrm{II})$-catalyzed transformation of the poorly crystalline iron mineral ferrihydrite. Biochim. Biophys. Acta - Gen. Subj. 1862, 1760-1769.

Yang L., Steefel C. I., Marcus M. A. and Bargar J. R. (2010) Kinetics of Fe(II)-catalyzed transformation of 6-line ferrihydrite under anaerobic flow conditions. Environ. Sci. Technol. 44, 5469-5475.

Yee N., Shaw S., Benning L. G. and Nguyen T. H. (2006) The rate of ferrihydrite transformation to goethite via the Fe(II) pathway. Am. Mineral. 91, 92-96.

Zhang D., Wang S., Wang Y., Gomez M. A., Duan Y. and Jia Y. (2018) The transformation of two-line ferrihydrite into crystalline products: effect of $\mathrm{pH}$ and media (sulfate versus nitrate). ACS Earth Sp. Chem. 2, 577-587.

Zheng K., Ngo P. D., Owens V. L., Yang X. P. and Mansoorabadi S. O. (2016) The biosynthetic pathway of coenzyme F430 in methanogenic and methanotrophic archaea. Science 354, 339-342.

Zhou Z., Latta D. E., Noor N., Thompson A., Borch T. and Scherer M. M. (2018) Fe(II)catalyzed transformation of organic matter-ferrihydrite coprecipitates: A closer look using Fe isotopes. Environ. Sci. Technol. 52, 11142-11150. 
Table 1. Results of structural model fitting of Zn K-edge EXAFS spectra.

\begin{tabular}{|c|c|c|c|c|c|c|}
\hline Sample & Shell & $\mathrm{N}^{a}$ & $\mathbf{R}(\AA)^{b}$ & $\sigma^{2}\left(\AA^{2}\right)^{c}$ & $\Delta \mathrm{E}_{0}(\mathrm{eV})^{d}$ & $\chi_{\mathrm{v}}^{2 e}$ \\
\hline \multirow[t]{2}{*}{ Zn-ferrihydrite } & $\mathrm{O}$ & $4.2(4)^{f}$ & $1.97(1)$ & $0.0064(9)$ & $0(1)$ & 18.88 \\
\hline & $\mathrm{Fe}$ & $6(2)$ & $3.45(1)$ & $0.017(3)$ & & \\
\hline \multirow[t]{4}{*}{ Zn-hematite } & $\mathrm{O}$ & 3 & $1.98(1)$ & $0.0052(9)$ & $1(2)$ & 13.32 \\
\hline & $\mathrm{O}$ & 3 & $2.20(2)$ & $0.013(3)$ & & \\
\hline & $\mathrm{Fe}$ & $3.5(3)$ & $2.98(1)$ & 0.008 & & \\
\hline & $\mathrm{Fe}$ & $1.4(4)$ & $3.33(2)$ & 0.008 & & \\
\hline \multirow[t]{2}{*}{ Zn adsorbed to hematite } & $\mathrm{O}$ & $6.2(5)$ & $2.014(6)$ & $0.012(1)$ & $-2(1)$ & 2.15 \\
\hline & $\mathrm{Fe}$ & $0.2(2)$ & $3.28(6)$ & 0.008 & & \\
\hline \multirow[t]{2}{*}{$0.2 \mathrm{mM} F \mathrm{Fe}(\mathrm{II}), 2 \mathrm{hr}$} & $\mathrm{O}$ & $3.9(5)$ & $1.966(8)$ & $0.006(1)$ & $1(1)$ & 14.64 \\
\hline & $\mathrm{Fe}$ & $6(3)$ & $3.43(2)$ & $0.018(5)$ & & \\
\hline \multirow[t]{4}{*}{$0.2 \mathrm{mM} \mathrm{Fe}(\mathrm{II}), 12 \mathrm{~d}$} & $\mathrm{O}$ & $3.0(2)$ & $1.98(1)$ & $0.004(1)$ & $1(2)$ & 3.30 \\
\hline & $\mathrm{O}$ & $1.6(2)$ & $2.14(2)$ & $0.004(1)$ & & \\
\hline & $\mathrm{Fe}$ & $0.8(2)$ & $2.98(2)$ & 0.008 & & \\
\hline & $\mathrm{Fe}$ & $0.7(3)$ & 3.39(3) & 0.008 & & \\
\hline \multirow[t]{2}{*}{$1.0 \mathrm{mM} F e(\mathrm{II}), 12 \mathrm{~d}$} & $\mathrm{O}$ & $4(1)$ & $1.97(1)$ & $0.005(2)$ & $1(2)$ & 15.44 \\
\hline & $\mathrm{Fe}$ & $18(5)$ & $3.50(2)$ & $0.015(3)$ & & \\
\hline
\end{tabular}

$874 \quad{ }^{\mathrm{a} C o o r d i n a t i o n ~ n u m b e r . ~}{ }^{\mathrm{b}}$ Interatomic distance. ${ }^{\mathrm{c}}$ Debye-Waller factor. ${ }^{\mathrm{d}}$ Difference in the threshold 875 Fermi level between data and theory. ${ }^{~}$ Reduced chi squared, a goodness-of-fit parameter (Kelly 876 et al., 2008). ${ }^{f}$ Values in parentheses are fitting uncertainties in the last digit, reported at the $1 \sigma$ 877 level. Parameters without uncertainties were held constant during fitting.

878

879

880 


\section{Figure Captions}

882 Figure 1. (a) XRD patterns of as-synthesized Zn-free ferrihydrite and Zn-ferrihydrite. (b) Data

883 (dotted) and structural model fit (lines) of Zn K-edge EXAFS spectra (left) and Fourier

884 Transform magnitude (right) of Zn-ferrihydrite.

885 Figure 2. XRD patterns of the solid phase products of Zn-ferrihydrite reaction with (top) 0.2 mM Fe(II) and (bottom) 1.0 mM Fe(II). Diagnostic peaks are labeled to indicate mineral phases:

887 F=ferrihydrite, L=lepidocrocite, $\mathrm{H}=$ hematite, $\mathrm{M}=$ =magnetite.

Figure 3. Fractional abundances of crystalline minerals (top) and of all minerals present

889 (bottom) determined by Rietveld refinement for reaction of $0.2 \mathrm{mM}$ dissolved Fe(II) with Zn-

890 ferrihydrite (left) or a Zn-free ferrihydrite control (right).

891 Figure 4. Fractional abundances of crystalline minerals (top) and of all minerals present 892 (bottom) determined by Rietveld refinement for reaction of $1.0 \mathrm{mM}$ dissolved Fe(II) with Zn893 ferrihydrite (left) or a Zn-free ferrihydrite control (right).

894 Figure 5. XRD patterns of (A) initial Zn-ferrihydrite (Zn-fh) and Zn-ferrihydrite aged for 12 895 days in the absence of Fe(II); (B) initial Zn-free ferrihydrite (fh) and Zn-free ferrihydrite reacted 896 with $0.2 \mathrm{mM}$ Fe(II) or $1.0 \mathrm{mM}$ Fe(II) for 12 days. Diagnostic peaks are labeled to indicate 897 mineral phases: $\mathrm{F}=$ ferrihydrite, $\mathrm{L}=$ =lepidocrocite, $\mathrm{H}=$ =hematite, $\mathrm{G}=$ goethite, $\mathrm{M}=$ =magnetite.

898 Figure 6. Dissolved Zn and Fe concentrations change with time during Zn-ferrihydrite 899 transformation induced by $0.2 \mathrm{mM} \mathrm{Fe}(\mathrm{II})$ and $1.0 \mathrm{mM} \mathrm{Fe(II)}$

900 Figure 7. Data (dotted) and structural model fit (lines) of Zn K-edge EXAFS spectra and Fourier 901 Transform magnitude of samples and standards associated with aging of Zn-ferrihydrite with 902 (top) $0.2 \mathrm{mM} \mathrm{Fe}(\mathrm{II})$ and (bottom) $1.0 \mathrm{mM} \mathrm{Fe(II).} \mathrm{Individual} \mathrm{spectra} \mathrm{are:} \mathrm{(a)} \mathrm{unreacted} \mathrm{Zn-}$ 
903 ferrihydrite; Zn-ferrihydrite reacted with $0.2 \mathrm{mM} \mathrm{Fe(II)} \mathrm{for} \mathrm{(b)} 2$ hours and (c) 12 days; (d) Zn

904 substituted in hematite; (e) Zn adsorbed to hematite; (f) Zn-ferrihydrite reacted with $1.0 \mathrm{mM}$

$905 \mathrm{Fe}(\mathrm{II})$ for 12 days; (g) franklinite $\left(\mathrm{ZnFe}_{2} \mathrm{O}_{4}\right)$.

906 Figure 8. Data (black circles) and linear combination fit (red line) of Zn K-edge EXAFS spectra

907 of Zn-ferrihydrite reacted with $0.2 \mathrm{mM} \mathrm{Fe(II)} \mathrm{for} 2$ hours and 12 days and with $1.0 \mathrm{mM} \mathrm{Fe(II)}$

908 for 12 days.

909

910

911

912

913 


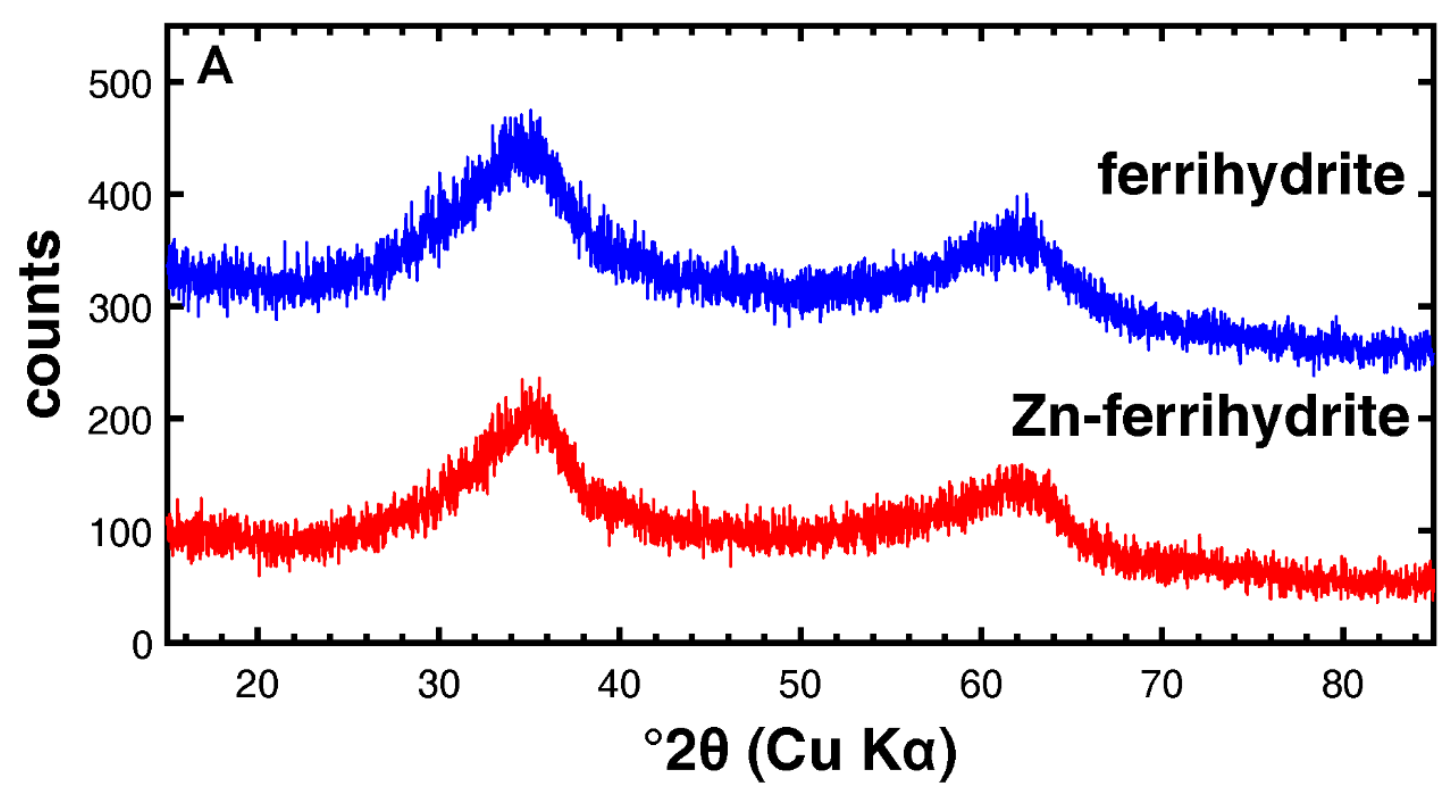

915
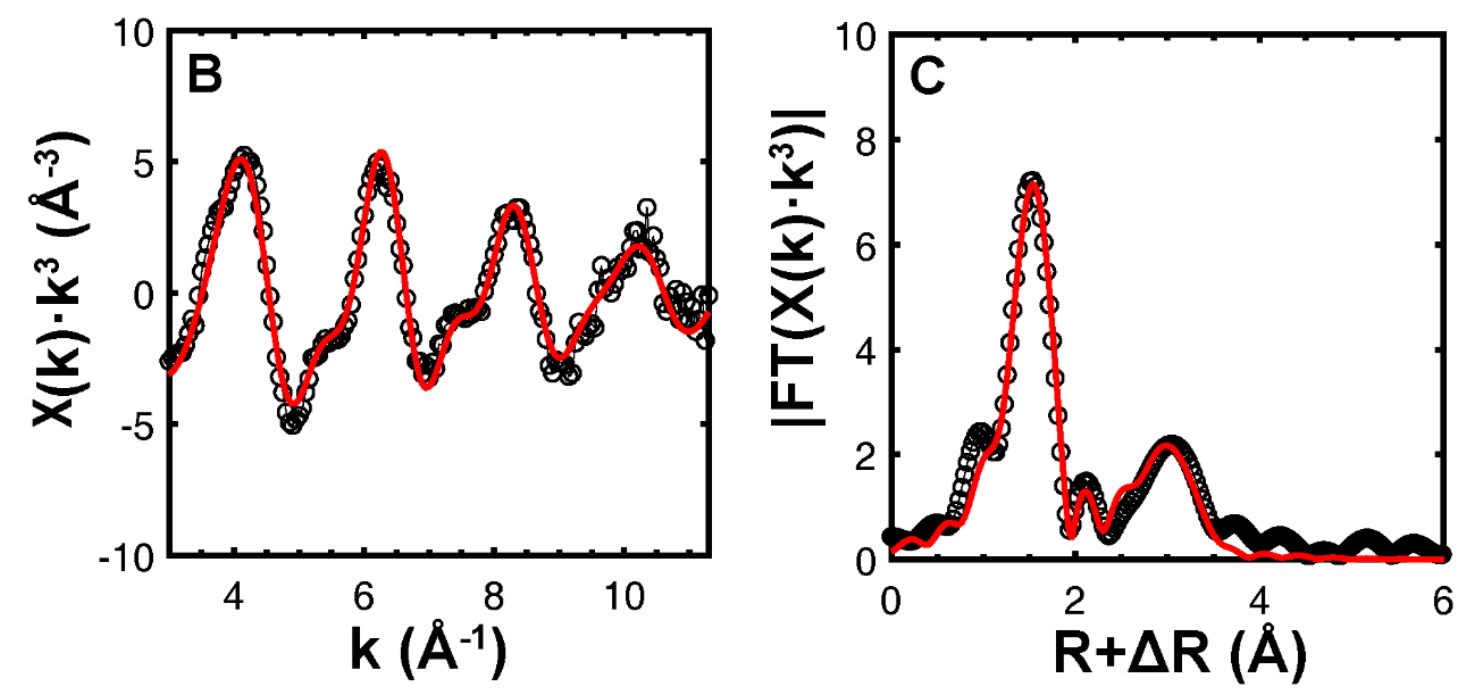

916 Figure 1. (a) XRD patterns of as-synthesized Zn-free ferrihydrite and Zn-ferrihydrite. (b) Data

917 (dotted) and structural model fit (lines) of Zn K-edge EXAFS spectra (left) and Fourier

918 Transform magnitude (right) of Zn-ferrihydrite. 

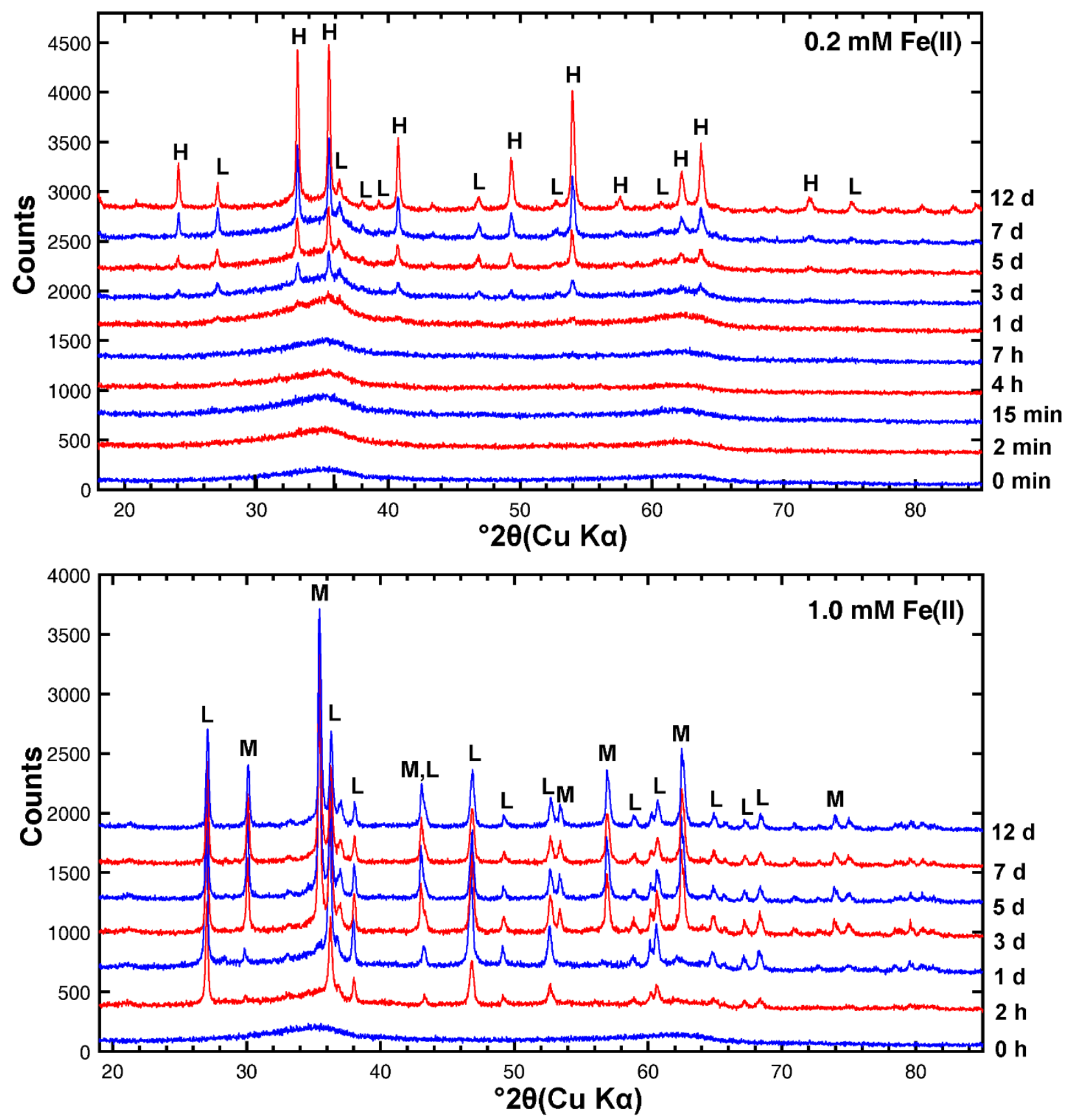

921 Figure 2. XRD patterns of the solid phase products of Zn-ferrihydrite reaction with (top) 0.2

$922 \mathrm{mM}$ Fe(II) and (bottom) $1.0 \mathrm{mM}$ Fe(II). Diagnostic peaks are labeled to indicate mineral phases:

923 F=ferrihydrite, $\mathrm{L}=$ =lepidocrocite, $\mathrm{H}=$ =hematite, $\mathrm{M}=$ =magnetite. 
Zn-ferrihydrite
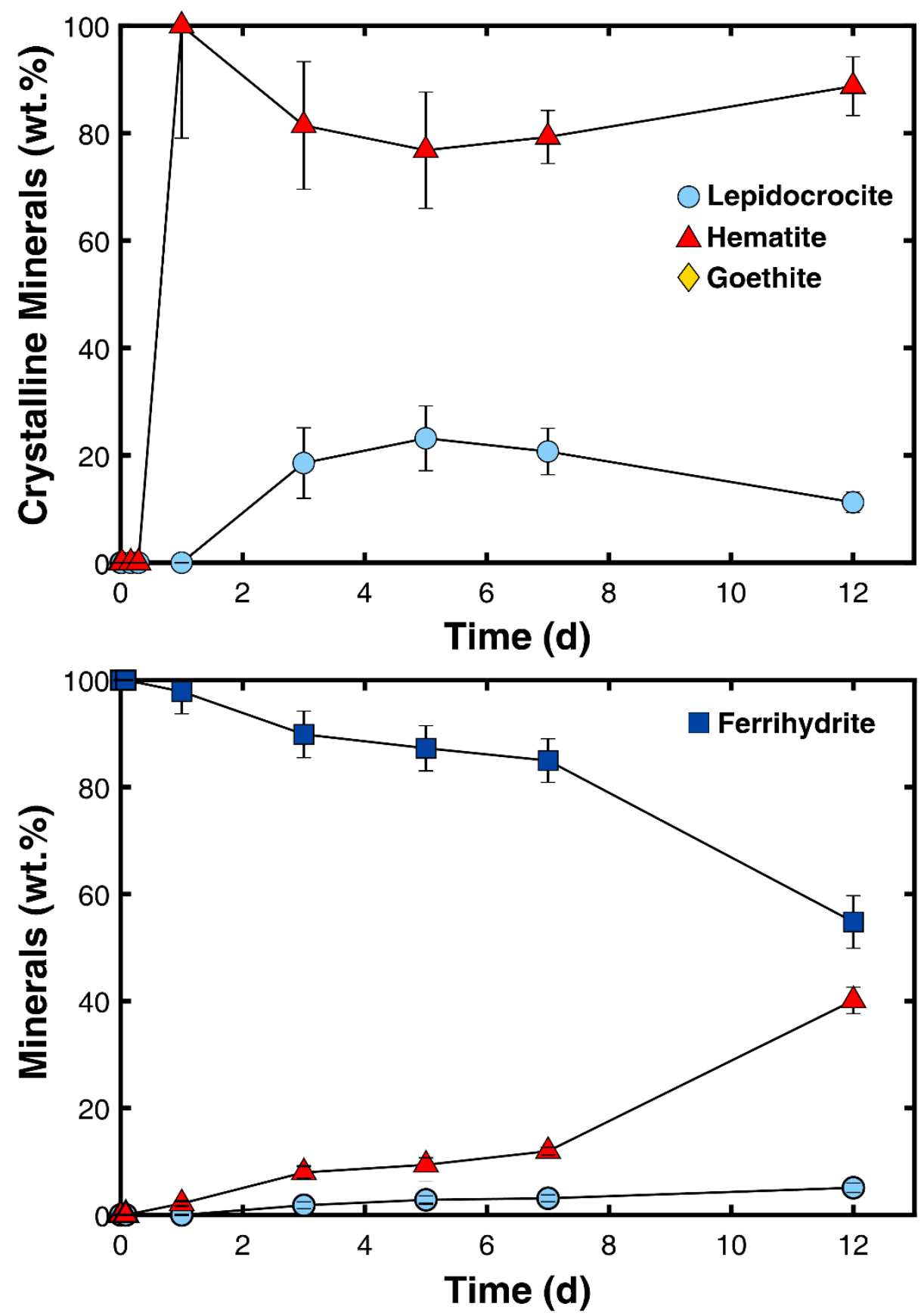

Control
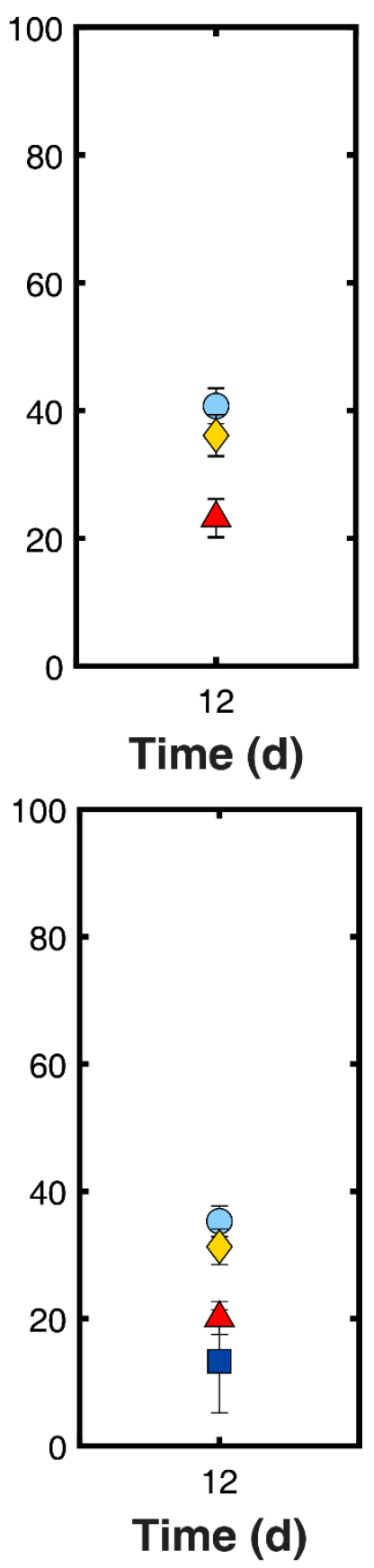

926 Figure 3. Fractional abundances of crystalline minerals (top) and of all minerals present

927 (bottom) determined by Rietveld refinement for reaction of $0.2 \mathrm{mM}$ dissolved Fe(II) with Zn-

928 ferrihydrite (left) or a Zn-free ferrihydrite control (right). 


\section{Zn-ferrihydrite}
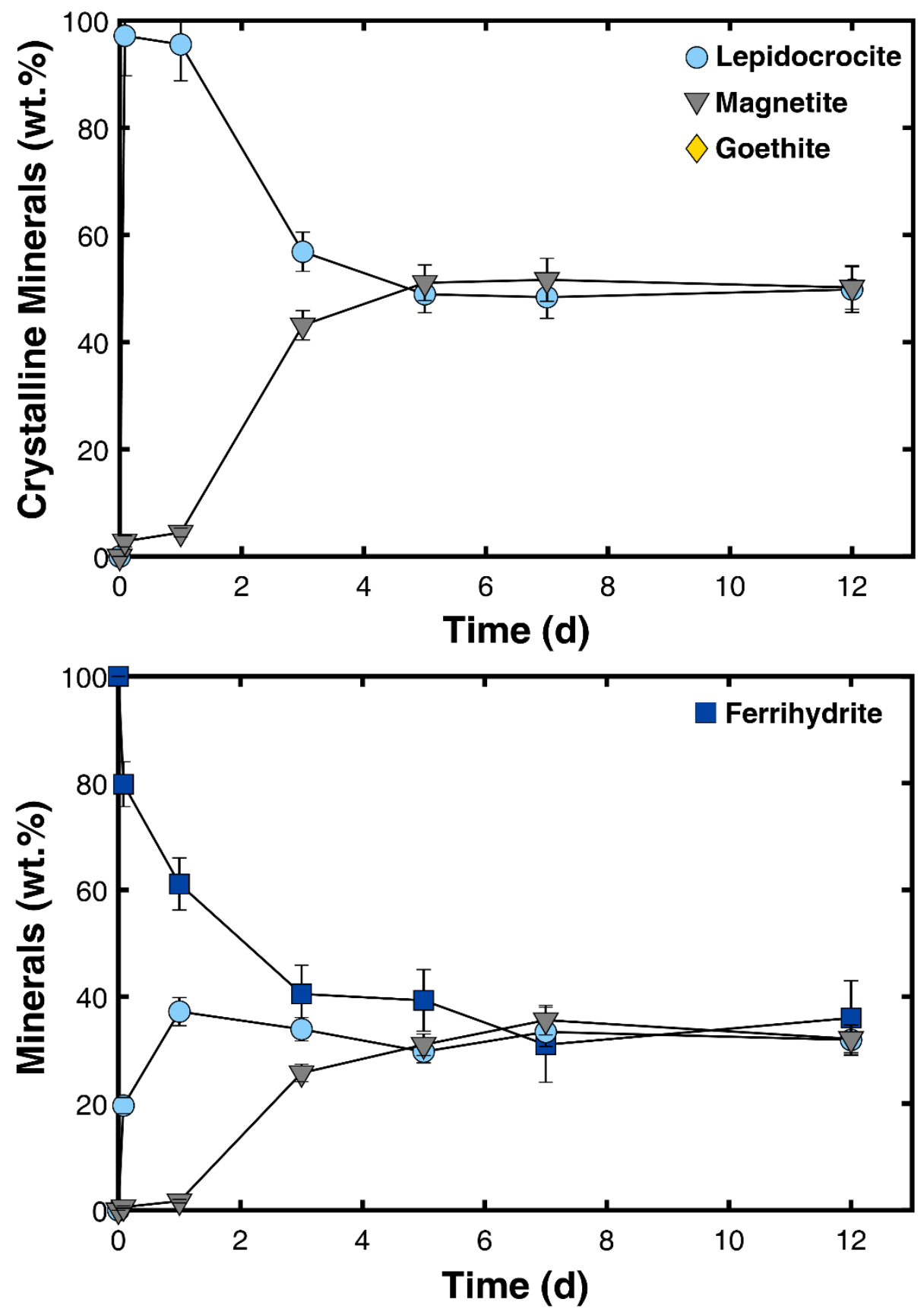

Control
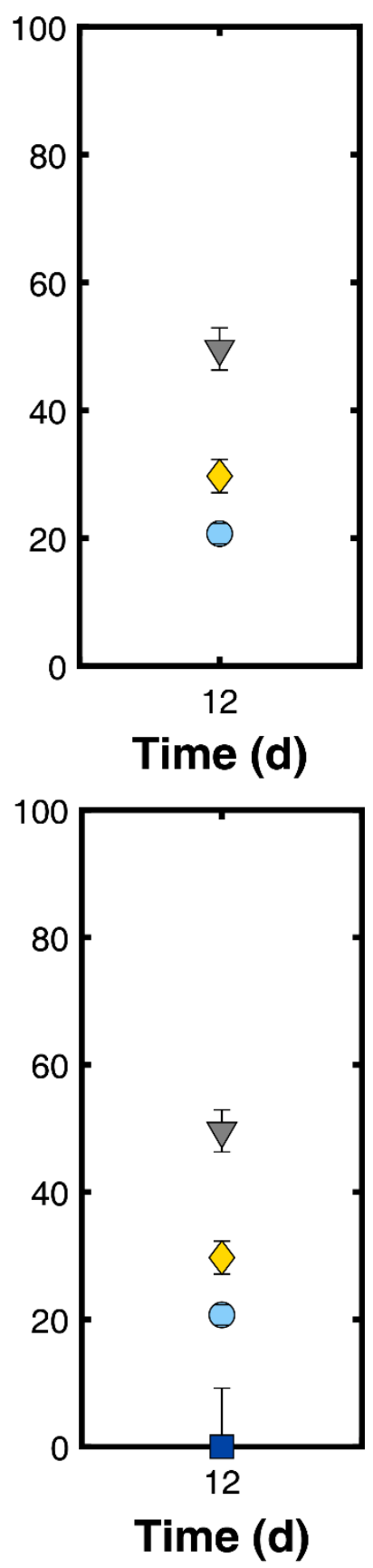

931 Figure 4. Fractional abundances of crystalline minerals (top) and of all minerals present

932 (bottom) determined by Rietveld refinement for reaction of $1.0 \mathrm{mM}$ dissolved Fe(II) with Zn-

933 ferrihydrite (left) or a Zn-free ferrihydrite control (right). 

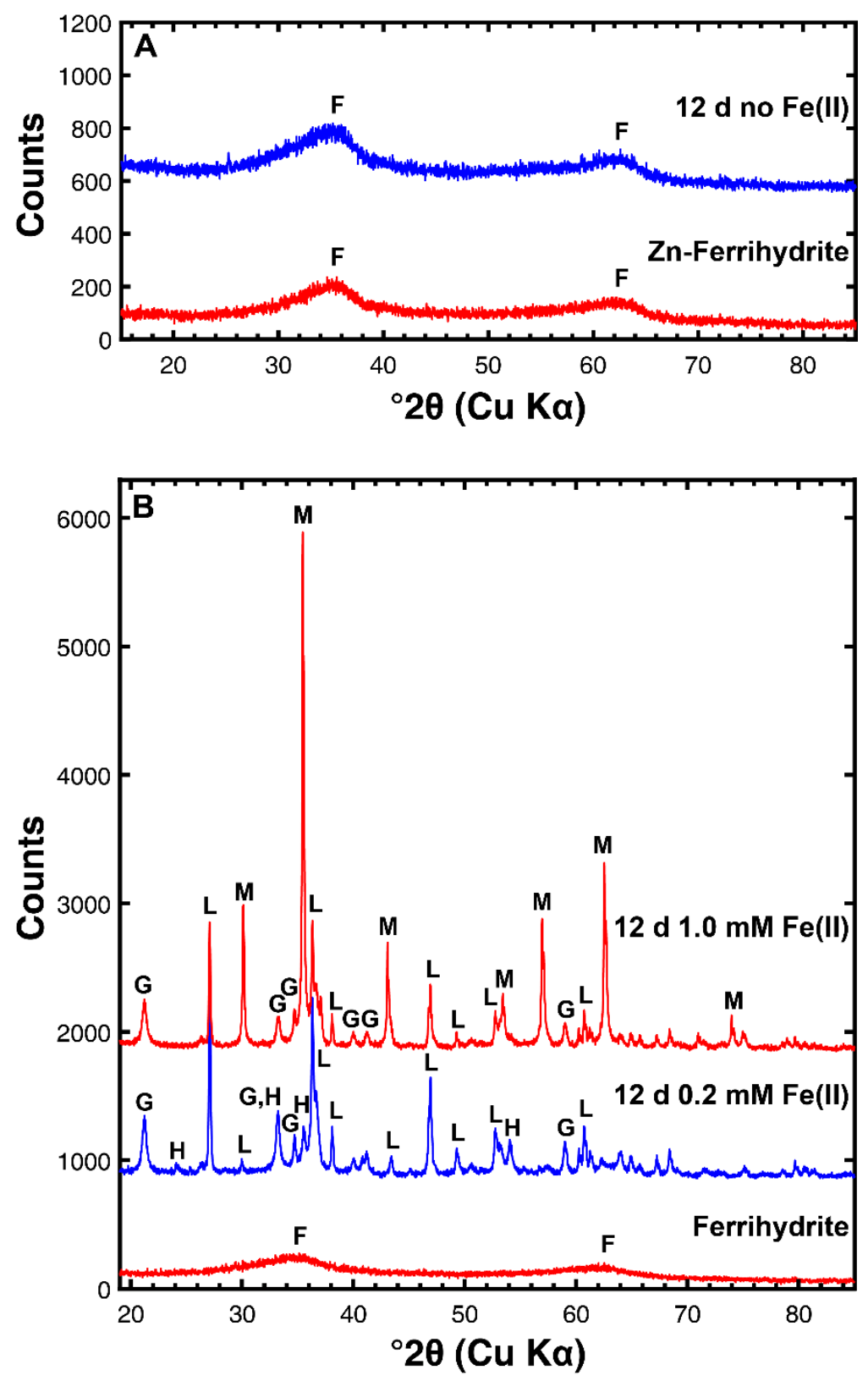

936 Figure 5. XRD patterns of (A) initial Zn-ferrihydrite (Zn-fh) and Zn-ferrihydrite aged for 12

937 days in the absence of Fe(II); (B) initial Zn-free ferrihydrite (fh) and Zn-free ferrihydrite reacted

938 with $0.2 \mathrm{mM}$ Fe(II) or $1.0 \mathrm{mM}$ Fe(II) for 12 days. Diagnostic peaks are labeled to indicate

939 mineral phases: $\mathrm{F}=$ =ferrihydrite, $\mathrm{L}=$ =lepidocrocite, $\mathrm{H}=$ hematite, $\mathrm{G}=$ goethite, $\mathrm{M}=$ =magnetite. 

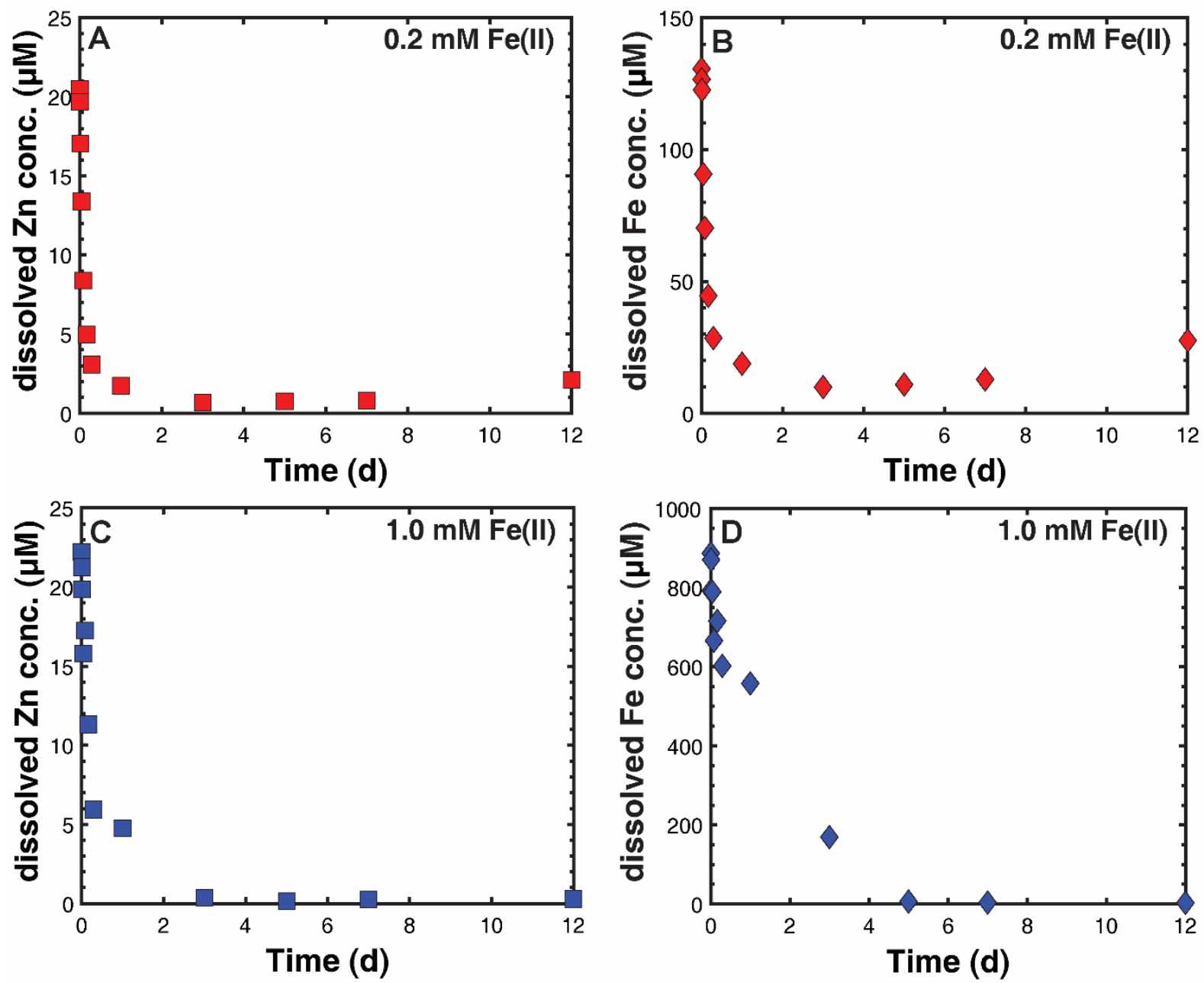

941 Figure 6. Dissolved Zn and Fe concentrations change with time during Zn-ferrihydrite

942 transformation induced by $0.2 \mathrm{mM} \mathrm{Fe(II)} \mathrm{and} 1.0 \mathrm{mM}$ Fe(II) 

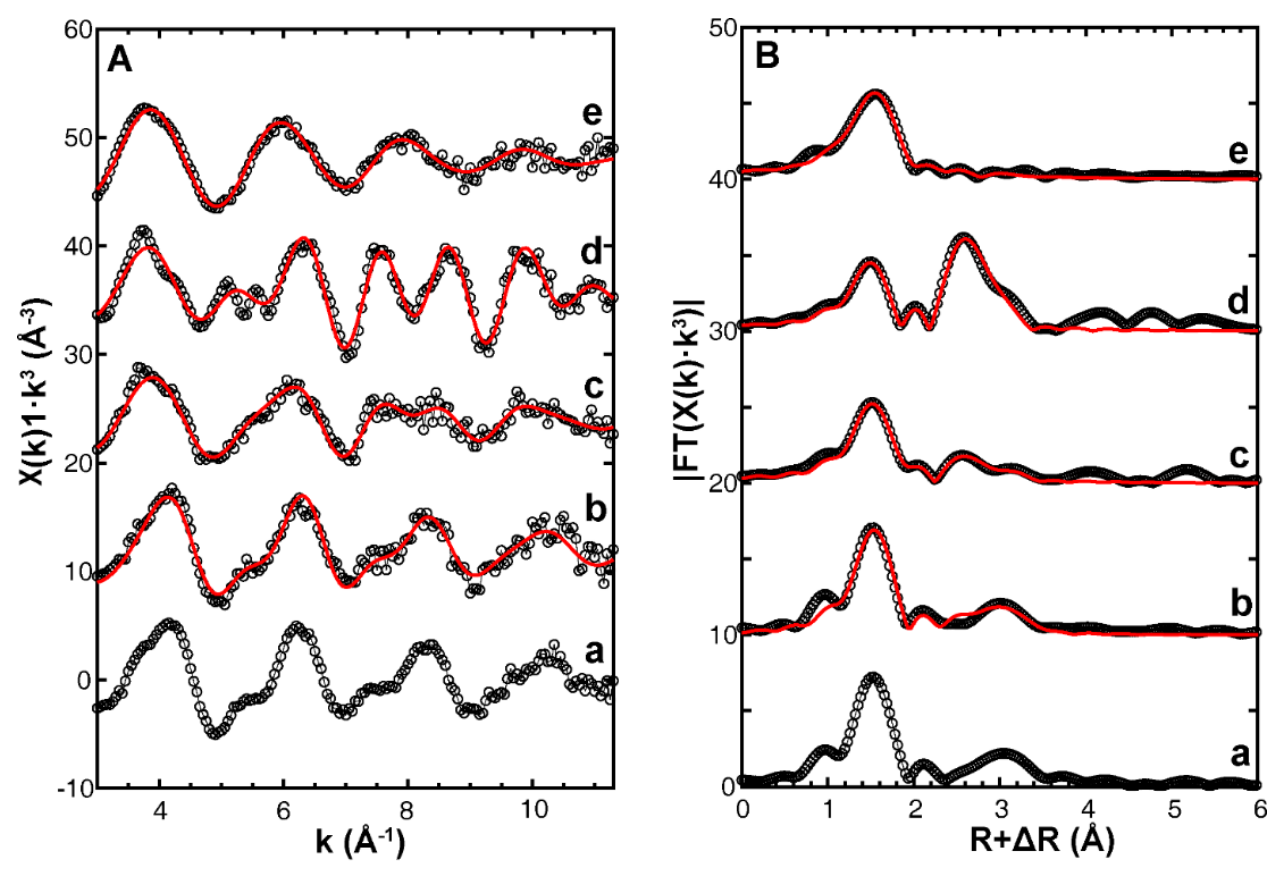

943
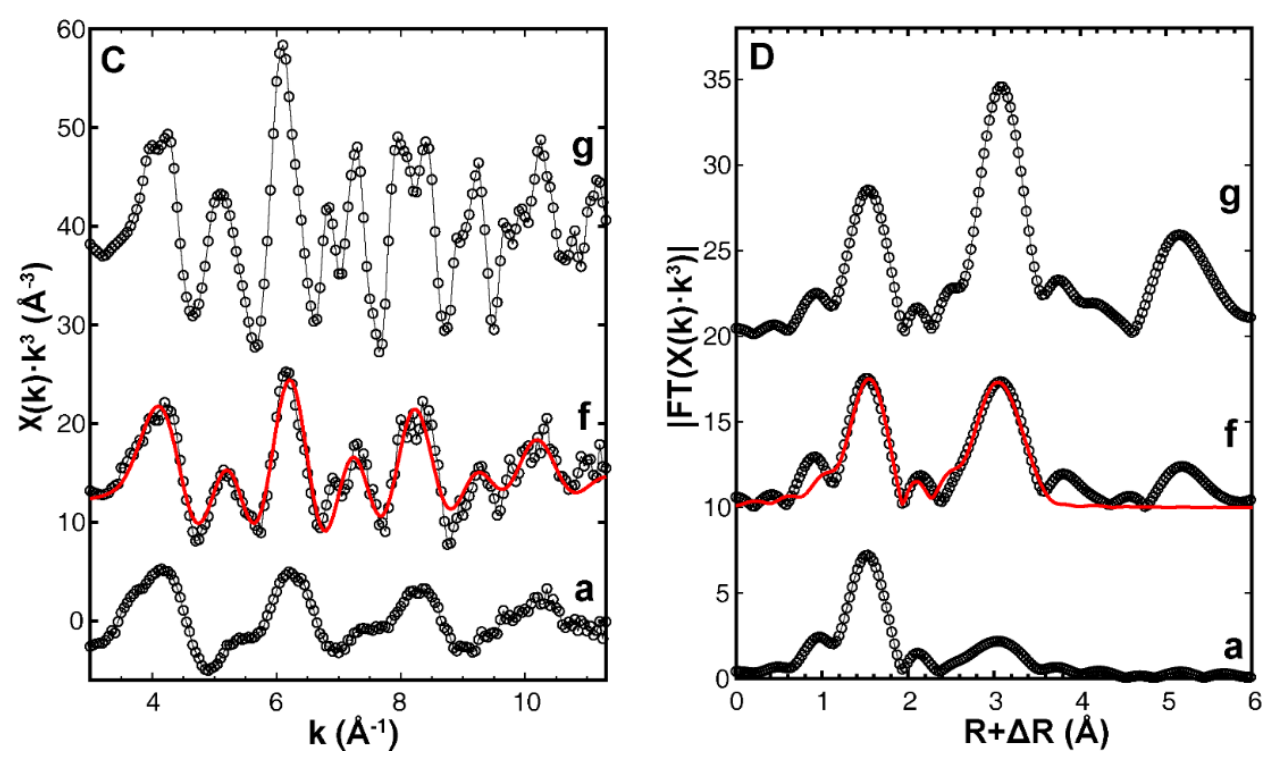

944 Figure 7. Data (dotted) and structural model fit (lines) of Zn K-edge EXAFS spectra and Fourier

945 Transform magnitude of samples and standards associated with aging of Zn-ferrihydrite with

946 (top) $0.2 \mathrm{mM} \mathrm{Fe(II)} \mathrm{and} \mathrm{(bottom)} 1.0 \mathrm{mM}$ Fe(II). Individual spectra are: (a) unreacted Zn-

947 ferrihydrite; Zn-ferrihydrite reacted with $0.2 \mathrm{mM}$ Fe(II) for (b) 2 hours and (c) 12 days; (d) Zn

948 substituted in hematite; (e) Zn adsorbed to hematite; (f) Zn-ferrihydrite reacted with $1.0 \mathrm{mM}$

$949 \mathrm{Fe}(\mathrm{II})$ for 12 days; (g) franklinite $\left(\mathrm{ZnFe}_{2} \mathrm{O}_{4}\right)$. 


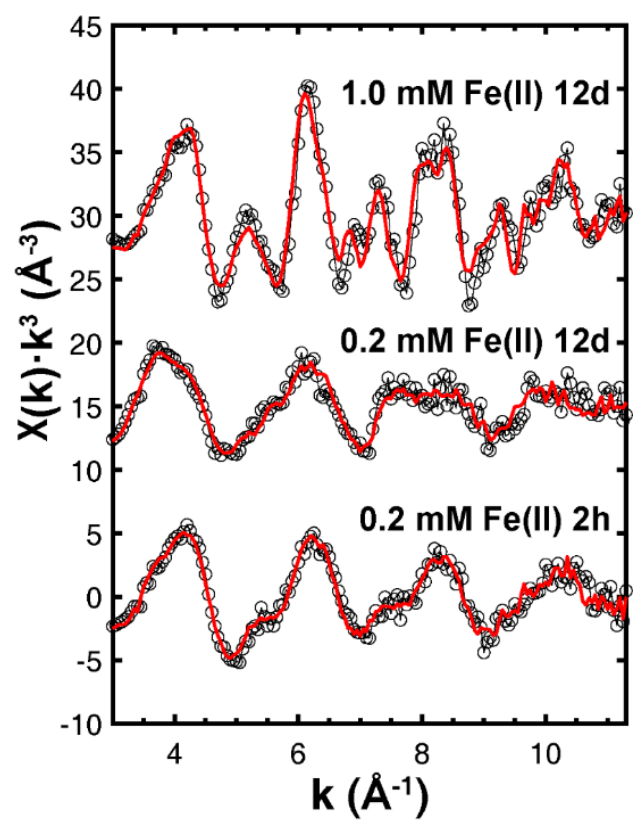

951 Figure 8. Data (black circles) and linear combination fit (red line) of Zn K-edge EXAFS spectra

952 of Zn-ferrihydrite reacted with $0.2 \mathrm{mM} \mathrm{Fe(II)} \mathrm{for} 2$ hours and 12 days and with $1.0 \mathrm{mM}$ Fe(II)

953 for 12 days.

954 
Supplementary Material for:

\title{
Impact of Zn Substitution on Fe(II)-induced Ferrihydrite Transformation Pathways
}

\author{
Jinshu Yan ${ }^{1}$, Andrew J. Frierdich ${ }^{2}$, and Jeffrey G. Catalano ${ }^{1^{*}}$ \\ 1. Department of Earth and Planetary Sciences, Washington University in St. Louis, Saint Louis, \\ MO 63130, USA \\ 2. School of Earth, Atmosphere \& Environment, Monash University, Clayton, VIC 3800, \\ Australia \\ *Corresponding author: catalano@wustl.edu
}

\section{Semi-Quantitative Ferrihydrite Abundance Determined via Rietveld Refinement}

The nanocrystalline nature of ferrihydrite precludes accurate simulation of its powder diffraction pattern, including the intensity of features. This prevents the use of Rietveld refinements for quantitative ferrihydrite determination using XRD data. However, full pattern simulation based on a fixed structural model and sample-specific parameters (e.g., peak broadening) that reproduces a measured pattern may provide a means for semi-quantitative analysis in a Rietveld framework under controlled experimental conditions. Full pattern calculations derived from a crystal structure provide scattering intensities determined from atomic scattering factors and thus should respond to abundance changes. However, the broad nature of ferrihydrite scattering features also pose challenges in distinguishing these from background, especially at low abundances.

The semi-quantitative analysis of ferrihydrite via Rietveld refinement was thus first evaluated using mixtures with a zinc oxide standard (U.S. National Bureau of Standards SRM 674). All analysis was conducted in the Profex interface to BGMN. First, the XRD pattern of synthetic Zn-ferrihydrite was simulated (Fig. 1) with the crystal structure of $2 \mathrm{~nm}$ ferrihydrite from (Michel 
28 et al., 2007). Only the lattice parameters and a peak broadening term were allowed to vary, and

29 the values from this initial analysis were then fixed for all subsequent analyses. Next, a series of

30 mixtures of ferrihydrite and zinc oxide, including both pure endmembers, were analyzed via

31 Rietveld refinement as a two-component mixture. The recovered ferrihydrite abundances (Fig. S1a)

32 varied linearly with true abundance but overestimated the ferrihydrite content as its concentration

33 decreased. A calibration curve between fitted and actual ferrihydrite abundance was generated

34 using linear regression, with the uncertainties on the slope and intercept propagated through

35 calculation of actual ferrihydrite abundance for unknown samples.

36 The accuracy of this calibration curve was next tested using data collected for synthetic

37 mixtures of ferrihydrite and hematite. The values derived from fitting the XRD patterns of these

38 mixtures via Rietveld refinement and then applying the calibration curve described above

39 generally well-reproduced the true ferrihydrite abundance within \pm 5 wt.\%, and within the one-

40 sigma fitting uncertainty for all but one sample (Fig. S1b,c). Fitting uncertainties are likely

41 underestimated at low ferrihydrite abundances because the calibration curve was generated using

42 unweighted linear regression. While a weighted linear regression to account for the different

43 uncertainties derived from Rietveld refinement of the initial ferrihydrite-zinc oxide data would

44 provide a more accurate estimate of the confidence interval, it is not trivial to then propagate this

45 through the calculation to derive actual ferrihydrite abundances. The ferrihydrite determination

46 should thus be viewed as semi-quantitative, primarily because of underestimated uncertainties as

47 the ferrihydrite-hematite mixtures suggest minimal systematic bias in the analysis. The absolute

48 abundances of crystalline phases when ferrihydrite is present should thus also be considered semi-

49 quantitative. The relative abundances of crystalline phases, however, remain quantitative. 


\section{Analysis of EXAFS Spectra of Zn Incorporated in and Adsorbed to Hematite}

52 The synthesis and characterization of Zn-substituted hematite was previously described

53 (Frierdich and Catalano, 2012). In that prior study, fitting a single oxygen shell to the EXAFS

54 spectrum yielded $4 \pm 1$ neighbors with an interatomic distance of $1.99 \pm 0.02 \AA$. This appeared to

55 suggested that zinc was tetrahedrally coordinated, but the multiple iron neighbors were consistent

56 with zinc occupying the iron site in the structure, which is a distorted octahedron. Recent

57 computational work (Bylaska et al., 2019) has demonstrated that zinc occupying this distorted

58 octahedron well reproduces the observed EXAFS spectrum. In the present work, the spectrum of

59 zinc substituted into hematite was thus fit with two oxygen shells comprised of three atoms each

60 (Figure 7A), to reflect the distorted octahedral site in hematite. This, along with the observed iron

61 neighbors (Table 1) is consistent with octahedral zinc occupying the distorted iron site in hematite.

62 The EXAFS spectrum of zinc adsorbed to hematite (Figure 7A) has more muted fine

63 structure, consistent with a surface complex. While the coordination number for oxygen (6.2 \pm 0.5$)$

64 suggests that zinc is octahedrally coordinated in this sample, the Zn-O distances is intermediate

65 between that of tetrahedral and octahedral zinc, indicating that a mixture of species are present.

66 The relative large $\sigma^{2}$ value for the shell indicates high disorder, as would be expected for a mix of

67 four- and six-coordinated zinc. An attempt to include a second shell contribution from iron yielded

68 a coordination number within error of zero. We attribute this to destructive interference between

69 iron shells for inner-sphere tetrahedral and octahedral zinc species rather than indicating that zinc

70 binds in an outer-sphere configuration.

71

72 

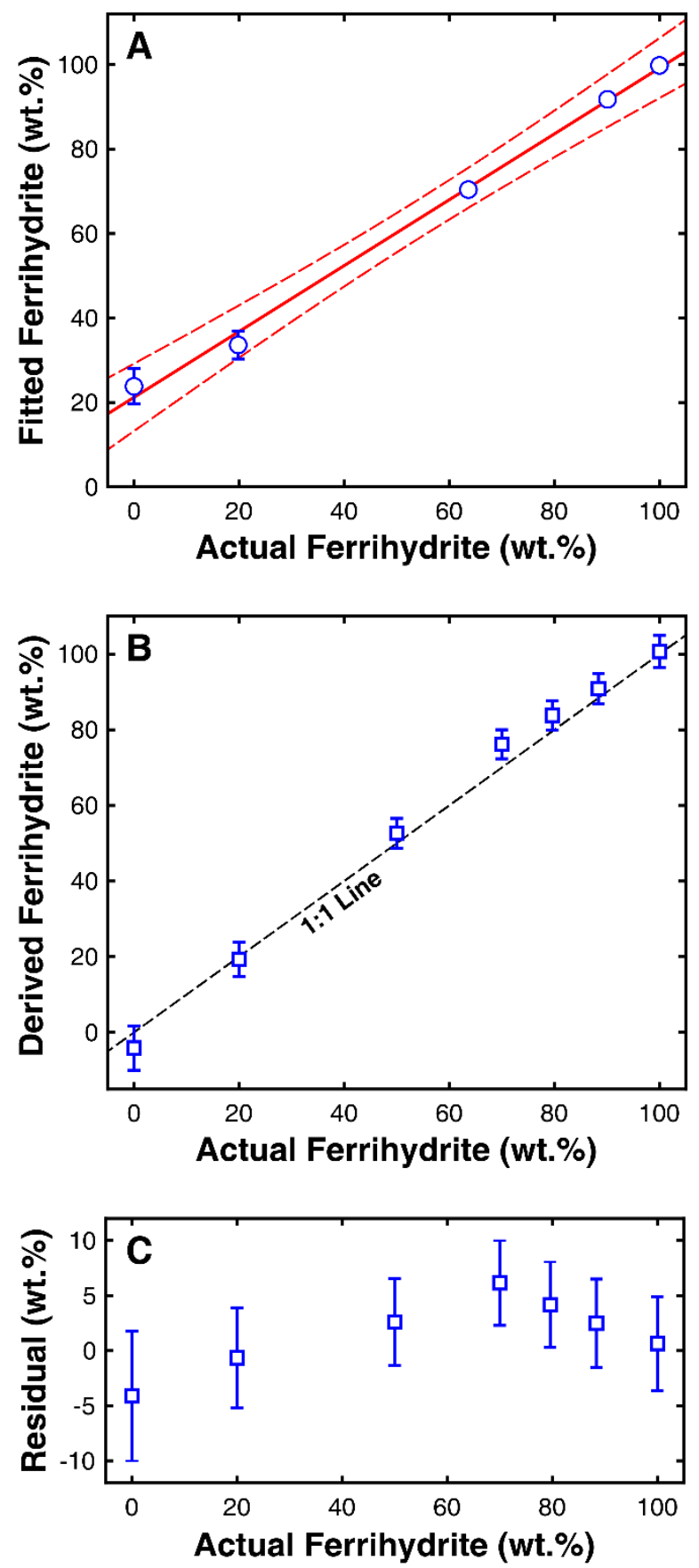

74 Figure S1. (A) Ferrihydrite abundances in 1:1 mixtures with zinc oxide versus actual ferrihydrite 75 abundances. Error bars represent the fitting uncertainty derived from Rietveld refinement; data 76 without errors have uncertainties smaller than the symbol. Also shown is the linear regression line 77 and 95\% confidence intervals. (B) Abundances of ferrihydrite in 1:1 mixtures with hematite 78 derived from Rietveld refinement using the empirical calibration curve obtained from zinc oxide 79 mixtures compared to actual abundances. Error bars account for both uncertainties obtained from 80 Rietveld refinement and in the calibration curve. (C) Residual values representing the difference 81 between derived and actual ferrihydrite abundances in mixtures with hematite. 


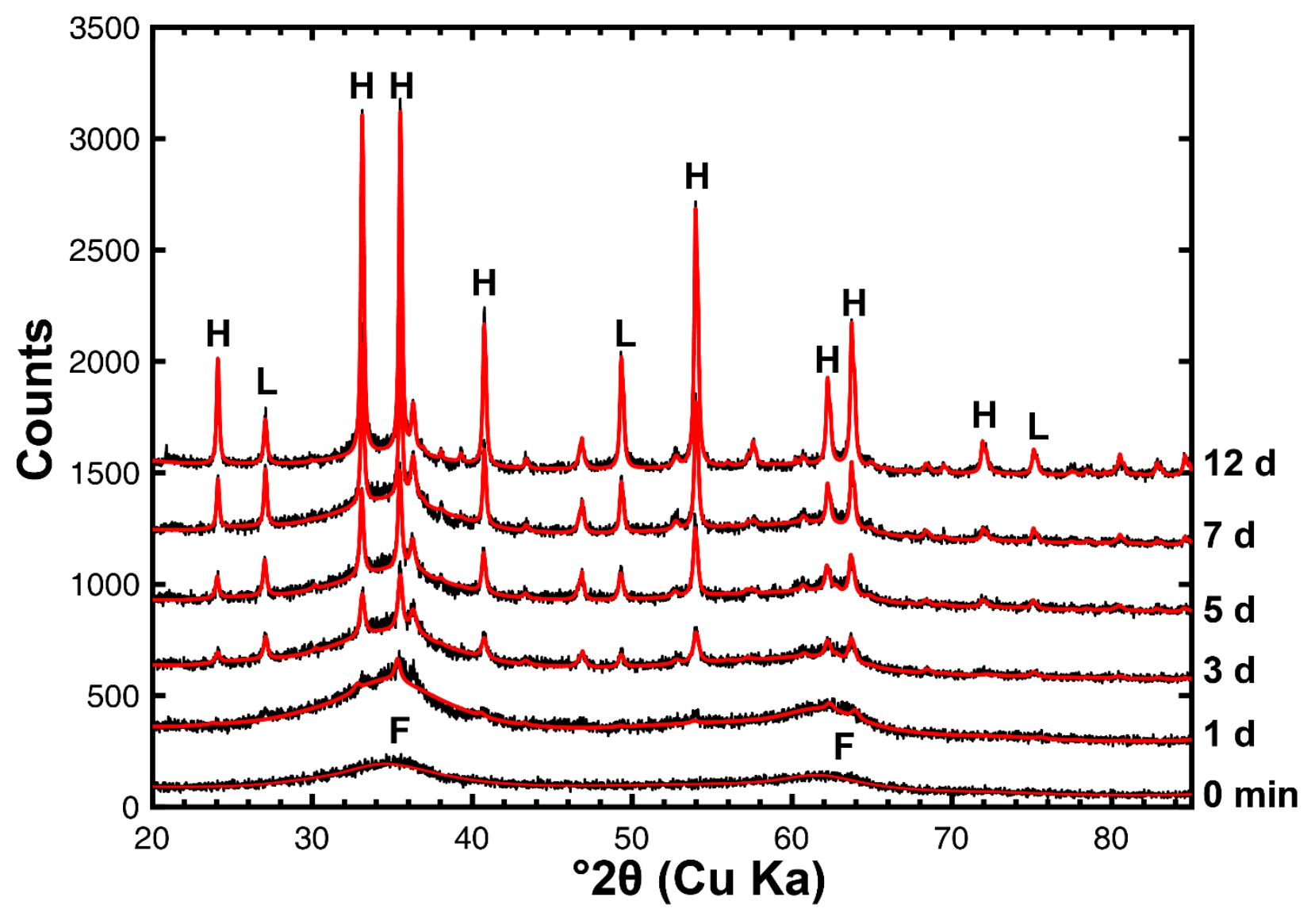

83 Figure S2. Rietveld refinement fit of XRD data (red) and XRD data (black) of mineral composition

84 changed over time during 12-day Zn-ferrihydrite transformation experiment in $0.2 \mathrm{mM}$ Fe(II) 


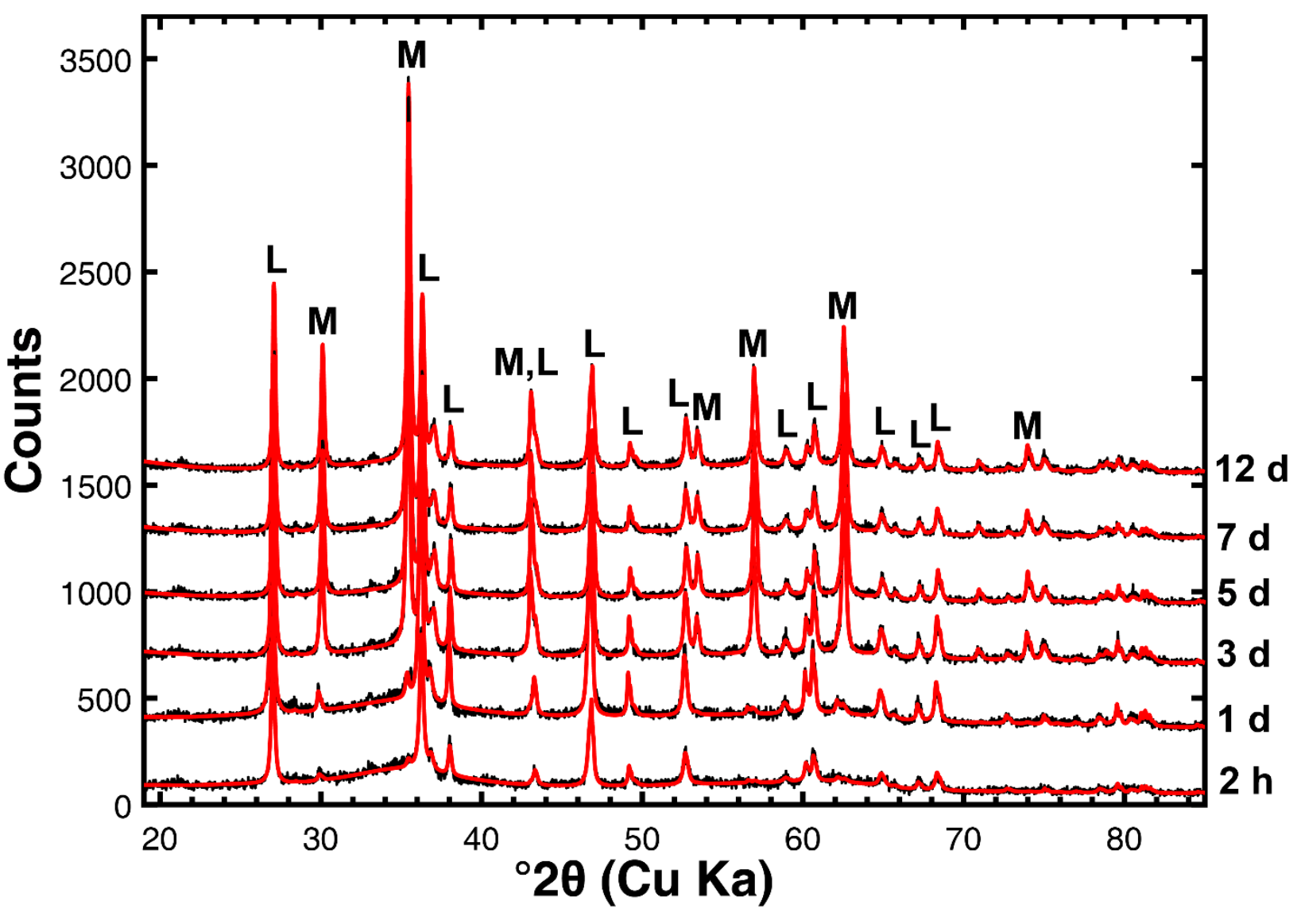

Figure S3. Rietveld refinement fit of XRD data (red) and XRD data (black) of mineral composition

88 changed over time during 12-day Zn-ferrihydrite transformation experiment in $1.0 \mathrm{mM}$ Fe(II) 


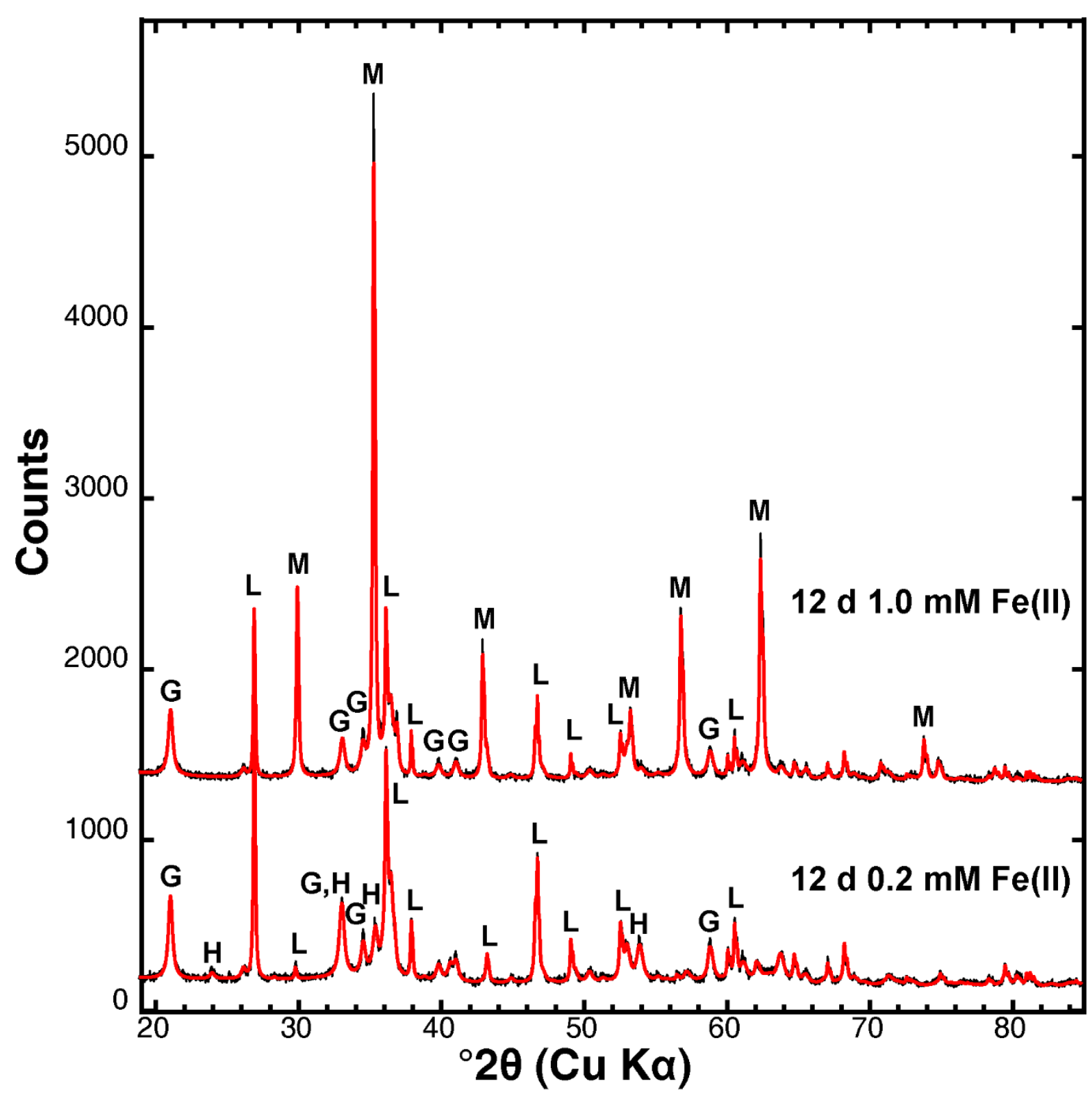

90

91

92

93

Figure S4. Rietveld refinement fit of XRD data (red) and XRD data (black) of mineral composition of the control experiments using Zn-free ferrihydrite. 

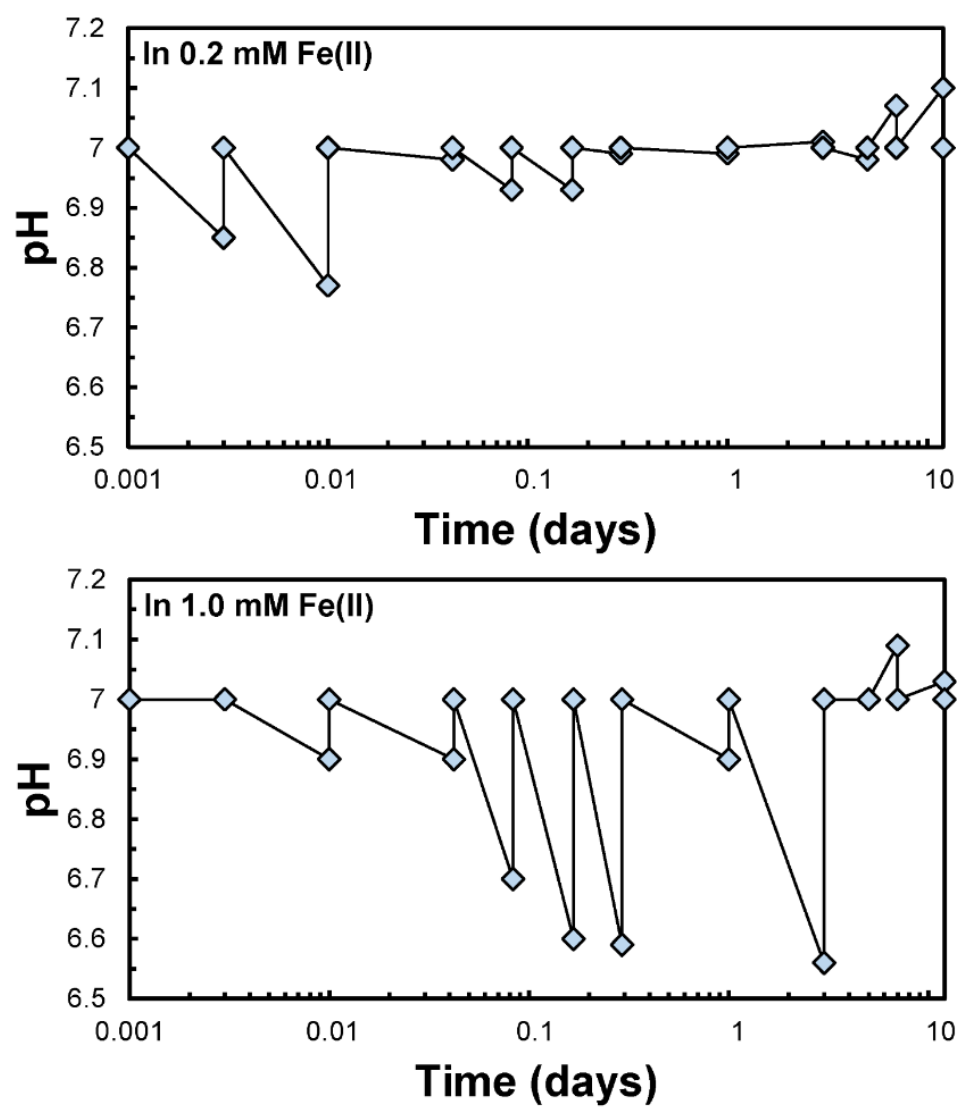

95 Figure S5. Drift in the $\mathrm{pH}$ during Zn-ferrihydrite transformation induced by $0.2 \mathrm{mM}$ or $1.0 \mathrm{mM}$

$96 \mathrm{Fe}(\mathrm{II})$. At each sampling point the $\mathrm{pH}$ was adjusted back to $7.0 \pm 0.1$ by dropwise addition of 0.1

$97 \mathrm{M} \mathrm{NaOH}$ 


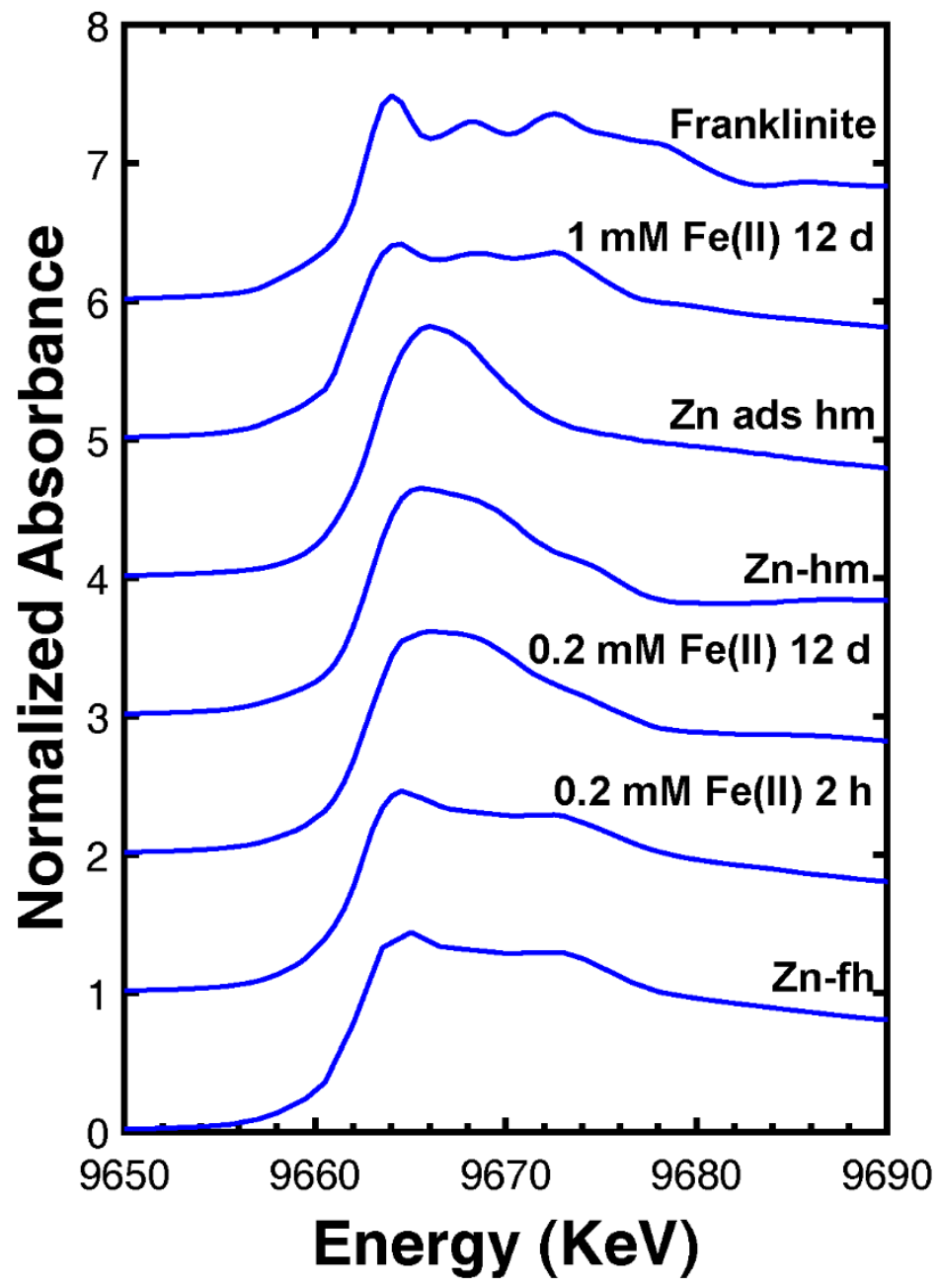

Figure S6. Zn K-edge XANES spectra of Zn-ferrihydrite (Zn-fh), Zn-ferrihydrite reacted with 0.2 $\mathrm{mM} \mathrm{Fe}(\mathrm{II})$ for 2 hours and 12 days, standards of Zn incorporated in (Zn-hm) and adsorbed on (Zn ads $\mathrm{hm}$ ) hematite, Zn-ferrihydrite reacted with $1.0 \mathrm{mM} \mathrm{Fe}(\mathrm{II})$ for 12 days, and franklinite. 
Table S1. parameters from Rietveld refinement of the XRD data and the mineral abundances after recalibration using the empirical ferrihydrite parameterization.

\begin{tabular}{|c|c|c|c|c|c|c|c|c|c|c|c|c|c|}
\hline \multirow{2}{*}{ Time } & \multicolumn{8}{|c|}{ Rietveld Refinement Results } & \multicolumn{5}{|c|}{ Recalibrated Abundances } \\
\hline & Fh (wt.\%) & Hem (wt.\%) & Lep (wt.\%) & Mag (wt.\%) & Goe (wt.\%) & $\mathrm{R}_{\mathrm{wp}}(\%)$ & $\mathrm{R}_{\exp }(\%)$ & $\chi^{2}$ & Fh (wt.\%) & Hem (wt.\%) & Lep (wt.\%) & Mag (wt.\%) & Goe (wt.\%) \\
\hline \multicolumn{14}{|l|}{$\begin{array}{l}0.2 \mathrm{mM} \\
\mathrm{Fe}(\mathrm{II}) \\
\end{array}$} \\
\hline $1 \mathrm{~d}$ & $97.9 \pm 0.2$ & $2.1 \pm 0.2$ & - & - & - & 8.86 & 7.32 & 1.47 & $98 \pm 4$ & $2.1 \pm 0.4$ & - & - & - \\
\hline $3 \mathrm{~d}$ & $90.0 \pm 0.5$ & $7.8 \pm 0.4$ & $1.8 \pm 0.2$ & $0.4 \pm 0.1$ & - & 8.86 & 7.84 & 1.28 & $90 \pm 4$ & $8 \pm 1$ & $1.8 \pm 0.6$ & $0.4 \pm 0.2$ & - \\
\hline $5 \mathrm{~d}$ & $87.6 \pm 0.4$ & $9.2 \pm 0.4$ & $2.8 \pm 0.2$ & $0.5 \pm 0.1$ & & 9.26 & 7.80 & 1.41 & $87 \pm 4$ & $9 \pm 1$ & $2.8 \pm 0.7$ & $0.5 \pm 0.3$ & - \\
\hline $7 \mathrm{~d}$ & $85.4 \pm 0.4$ & $11.6 \pm 0.2$ & $3.0 \pm 0.2$ & - & - & 9.13 & 7.51 & 1.48 & $85 \pm 4$ & $11.9 \pm 0.7$ & $3.1 \pm 0.7$ & - & - \\
\hline $12 \mathrm{~d}$ & $59.5 \pm 0.9$ & $36.0 \pm 0.7$ & $4.6 \pm 0.3$ & - & - & 9.65 & 7.50 & 1.66 & $55 \pm 5$ & $40 \pm 3$ & $5 \pm 1$ & - & - \\
\hline Control & $29.6 \pm 1.6$ & $16.3 \pm 0.7$ & $28.7 \pm 0.7$ & - & $25.4 \pm 0.8$ & 9.41 & 7.91 & 1.42 & $13 \pm 8$ & $20 \pm 3$ & $35 \pm 2$ & - & $31 \pm 3$ \\
\hline \multicolumn{14}{|l|}{$\begin{array}{l}1.0 \mathrm{mM} \\
\mathrm{Fe}(\mathrm{II})\end{array}$} \\
\hline $2 \mathrm{~h}$ & $80.7 \pm 0.5$ & - & $18.7 \pm 0.5$ & $0.6 \pm 0.1$ & - & 11.12 & 9.35 & 1.41 & $80 \pm 4$ & - & $20 \pm 2$ & $0.6 \pm 0.2$ & - \\
\hline $1 \mathrm{~d}$ & $64.6 \pm 0.8$ & - & $33.8 \pm 0.8$ & $1.6 \pm 0.1$ & - & 10.64 & 8.09 & 1.73 & $61 \pm 5$ & - & $37 \pm 3$ & $1.7 \pm 0.3$ & - \\
\hline $3 \mathrm{~d}$ & $48.5 \pm 1.0$ & - & $29.3 \pm 0.6$ & $22.2 \pm 0.5$ & - & 10.45 & 8.05 & 1.69 & $41 \pm 5$ & - & $34 \pm 2$ & $26 \pm 2$ & - \\
\hline $5 \mathrm{~d}$ & $47.6 \pm 1.1$ & - & $25.6 \pm 0.6$ & $26.8 \pm 0.6$ & - & 11.66 & 8.86 & 1.73 & $39 \pm 6$ & - & $30 \pm 2$ & $31 \pm 2$ & - \\
\hline $7 \mathrm{~d}$ & $41.7 \pm 1.4$ & - & $28.2 \pm 0.8$ & $30.1 \pm 0.8$ & - & 11.74 & 8.90 & 1.74 & $31 \pm 7$ & - & $33 \pm 3$ & $36 \pm 3$ & - \\
\hline $12 \mathrm{~d}$ & $45.2 \pm 1.4$ & - & $27.3 \pm 0.8$ & $27.5 \pm 0.7$ & - & 12.85 & 8.78 & 2.14 & $36 \pm 7$ & - & $32 \pm 3$ & $32 \pm 3$ & - \\
\hline Control & $16.9 \pm 1.9$ & - & $17.2 \pm 0.5$ & $41.2 \pm 0.9$ & $24.7 \pm 0.7$ & 10.20 & 7.89 & 1.67 & $0 \pm 9$ & - & $21 \pm 2$ & $50 \pm 3$ & $30 \pm 3$ \\
\hline
\end{tabular}

$*$ Mineral labels: ferrihydrite $=$ Fh, hematite $=$ Hem, lepidocrocite $=$ Lep, magnetite $=$ Mag, goethite $=$ Goe. 


\section{REFERENCES}

Bylaska E. J., Catalano J. G., Mergelsberg S. T., Saslow S. A., Qafoku O., Prange M. P. and Ilton E. S. (2019) Association of Defects and Zinc in Hematite. Environ. Sci. Technol. 53, 13687-13694.

Frierdich A. J. and Catalano J. G. (2012) Controls on Fe(II)-activated trace element release from goethite and hematite. Environ. Sci. Technol. 46, 1519-1526.

Michel F. M., Ehm L., Antao S. M., Lee P. L., Chupas P. J., Liu G., Strongin D. R., Schoonen M. A. A., Phillips B. L. and Parise J. B. (2007) The structure of ferrihydrite, a nanocrystalline material. Science. 316, 1726-1729. 